\title{
The influence of vegetation and surrounding traffic noise parameters on the sound environment of urban parks
}

\author{
Efstathios MARGARITIS ${ }^{1}$; Jian KANG ${ }^{2}$ Karlo FILIPAN³ Dick BOTTELDOOREN ${ }^{4}$
}

\begin{abstract}
Affiliation:
1,2 School of Architecture, University of Sheffield, Sheffield, United Kingdom

3,4 Department of Information Technology, Ghent University, Ghent, Belgium
\end{abstract}

Email address:

e.margaritis@sheffield.ac.uk (E. Margaritis)

j.kang@sheffield.ac.uk (J. Kang)

karlo.filipan@intec.ugent.be (K. Filipan)

dick.botteldooren@intec.ugent.be (D. Botteldooren)

* Corresponding author: Efstathios Margaritis

Postal address: School of Architecture, University of Sheffield, Western Bank,

Arts Tower - S10 2TN Sheffield (UK)

Email:e.margaritis@sheffield.ac.uk

\section{Acknowledgements}

This research received funding from the People Programme (Marie Curie Actions) of the European Union's Seventh Framework Programme FP7/2007-2013 under REA grant agreement $n^{\circ} 290110$, SONORUS "Urban Sound Planner". The authors are grateful to Dr. Luc Dekoninck for organising the traffic data obtained from the Traffic Centre in Flanders and Tirthankar Chakraborty for his valuable help in the analysis of the data under the Postgraduate Advantage Scheme (PAS) of the University of Sheffield. 


\section{Introduction}

2 Traffic noise has been closely related to health issues (Bodin et al., 2009; Fyhri \& Klæboe, 2009;

3 Pirrera, De Valck, \& Cluydts, 2010; Selander et al., 2009). In particular, according to the review

4 report from the Environmental Burden of Disease (EBD) (Hänninen et al., 2014) noise was

5 ranked second among the selected environmental stressors evaluated in terms of their public

6 health impact in six European countries.

7 The Environmental Noise Directive (END) (2002/49/EC) - through the Noise Action Plans - has

8 made an attempt to quantify the percentage of people living within critical areas of high noise

9 levels. However, the noise levels reported in the END are based on the results of traditional noise

10 mapping methods based on simulations of annual average traffic data and refer to a strategic

11 level. Moreover, in practice, measurement campaigns found significant deviations between

12 measured and calculated acoustical indicators (De Coensel et al., 2015), especially in shielded

13 zones or quiet areas (Wei et al., 2016).

14 At the same time the technological boost in acoustic measurement devices has made the

15 acquisition of real-time noise data much easier either through mobile phones (D'Hondt, Stevens,

16 \& Jacobs, 2013; Guillaume et al., 2016; Maisonneuve et al., 2009; Murphy \& King, 2016; Rana

17 et al., 2015) or through the use of portable devices (Can \& Gauvreau, 2015; Filipan et al., 2014).

18 These methods can be used in the production of the so-called "dynamic noise maps" with various

19 models being proposed (Can et al., 2010; Cho, Kim, \& Manvell, 2007; De Coensel et al., 2005;

20 Gereb, 2013; Ma \& Cai, 2013; Szczodrak et al., 2013; Wei et al., 2016;). The increased accuracy

21 of dynamic noise mapping in shielded or quiet areas makes this method more appropriate in

22 noise level calculation within green areas and parks, the importance of which has also been 
highlighted in the "Good Practise Guide on Quiet Areas" (EEA Techical Report, 2014) and other studies (De Ridder et al., 2004; Gidlöf-Gunnarsson \& Öhrström, 2007).

From the noise perspective, previous studies pointed out the importance of vegetation on traffic noise mitigation through the use of trees, tree belts, plants or hedges (Aylor, 1972; Huddart, 1990; Jang et al., 2015; Kragh, 1981; Van Renterghem, Botteldooren, \& Verheyen, 2012). The above references provide general guidelines or refer to the specific experimental conditions. On a broader scale, the latest studies assessing noise level distribution have applied regression models using morphological and land use parameters (Aguilera et al., 2015; Margaritis \& Kang, 2017; Ryu et al., 2017). The same regression-based approach has also been applied in soundscape mapping with physical, acoustic and perceptual data using different interpolation techniques (Hong \& Jeon, 2017). Complementary to these tools, clustering techniques are also important in the identification of "cold" and "hot" spots in large noise datasets. Such tools are provided in ArcGIS (v.10.3.1) and belong in the category of local spatial pattern analysis tools (Hot Spot Analysis-Getis-Ord Gi*, Local Moran's I). In this study the Hot Spot Analysis tool was used, which is able to identify whether features with either high or low values cluster spatially. Since the main interest lies in the identification of the regular patterns, the use of the Local Moran's I tool was avoided, as it is appropriate for the detection of spatial outliers. The latter are just a few points throughout the parks and comprise the exception cases. Especially for noise distribution in parks, most of the studies have dealt with a combination of measured noise levels (Zannin, Ferreira, \& Szeremetta, 2006) and perceptual parameters based on users' experience (Aletta et al., 2015; Brambilla \& Maffei, 2006; Filipan et al., 2014; Liu et al., 2014a; Nilsson \& Berglund, 2006; Szeremeta \& Zannin, 2009). In particular, Brambilla et al., (2013) found that non acoustical parameters, such as vegetation and natural sounds improve the 
46 soundscape quality of parks, even when these sites exceed the objective acoustic threshold of

47 “quiet” areas (50 dBA). A similar study in Milan by Brambilla, Gallo, \& Zambon, (2013)

48 revealed that "soundscape quality" prevailed over "quietness", confirming that the latter

49 parameter is just one aspect of soundscape appraisal. These examples led Brambilla \& Gallo,

50 (2016) to develop a new index for assessing the environmental quality of urban parks using the

51 perceived overall quality and objective noise indices. In the same wavelength, Cohen et al.,

52 (2014) used in-situ noise levels as one of the proposed elements of a methodological framework for

53 the assessment of the environmental quality of urban parks. Finally, other authors (Kang et al., 2013;

54 Schulte-Fortkamp \& Jordan, 2016) have included noise levels in parks as part of various active

55 soundscape interventions in order to mask the unwanted traffic sounds.

56 However, very few studies have tried to describe the perception of tranquility in green areas

57 based exclusively on physical parameters related to green space features. For example,

58 González-Oreja, Bonache-Regidor, \& De La Fuente-Díaz-Ordaz (2010) used the park size and

59 the tree canopy as predictors for noise levels, while Pheasant, Horoshenkov, \& Watts (2010)

60 introduced the "Tranquillity Rating Prediction Tool” (TRAPT), which predicts perceptual

61 tranquillity based on the sound pressure levels and the ratio of natural features in the scene.

62 Although this tool has been validated, it is designed to assess specific sceneries within a

63 restricted visual depth. Nevertheless, the assessment of tranquillity and noise distribution when

64 investigating parks as entities needs to be broader, considering also the urban morphology of the

65 surrounding environment.

66 Consequently, the main aim of this study is to investigate the influence of vegetation and traffic-

67 related parameters on the sound environment in urban parks based on physical data. This aim is

68 achieved through the following objectives: (1) investigation of noise level distribution in the park 
69 scale caused exclusively by the simulated surrounding traffic, (2) investigation of noise level

70 distribution in point scale according to the recorded noise levels inside the parks, (3)

71 identification of possible patterns in the noise measurements based on the inside-outside

72 relationship and (4) identification of possible correlations between the green space attributes of

73 the parks and other morphological parameters, 5) presentation of noise level differences based on

74 vegetation coverage parameters analysed in a park and index-based scale.

\section{2. Methods}

\section{$76 \quad$ 2.1. Case study sites}

77 The data presented in this study were collected in eight urban parks in Antwerp, Belgium.

78 Antwerp is the largest city in Flanders and the second largest city in Belgium. A big part of the

79 city's economy is a major European harbour, which has its incoming and outgoing traffic routes

80 along the city. Additionally, Antwerp's ring road is integrated in the Trans-European Traffic

81 Network (TENtec). Therefore, traffic creates substantial noise problems for the surrounding

82 urban areas.

83 All data were collected in cooperation with the Environmental Authority of Antwerp's City

84 Council. The investigated parks shown in Fig.1 spread over the whole city and are accessible to a

85 large number of people. Additionally, they present significant variations in the distance from the

86 Ring or the National road, as well as the variability in size and green space coverage, which

87 renders them representative for the whole study area. Details are provided in Table 1, while the

88 location of the parks within the city can be seen in Fig.1.

89 Table 1

$90 \quad$ Fig.1 
92 The green space data for this study were selected from tree and grass coverage in dichotomous terms rather than interval since it is expected that at the urban level this would provide enough

94 information about the vegetation coverage. Green space features were identified from the World 95 Imagery basemap available by ESRI. This layer provides an imagery resolution of “ $0.3 \mathrm{~m}$ ” 96 regarding Western Europe and at least " $1 \mathrm{~m}$ " in many parts of the world (ESRI, 2016a). The 97 green space characteristics were recognised for each park using the ArcGIS software (v. 10.3.1) 98 and the Maximum Likelihood Classification tool (ESRI, 2016b).

99 At first, all park images were imported in Photoshop (v.CS5), where certain steps were followed to facilitate the classification process in ArcGIS. Specifically, the tools of "Brightness" and

101 "Contrast" were used to make the differences between the shadows and the canopy more evident. 102 A slight increase of the green colour in the "Colour Balance" menu was used to further highlight 103 these differences in some parks. All images were then georeferenced in ArcGIS in accordance 104 with the vector park borders.

105 In the next step, the green space classes were distinguished along with the results of the 106 supervised classification process, which involved the collection of training samples for each 107 category. The ultimate recognised classes were formed as follows: "trees", "grass" and "other" 108 all built in a raster of $30 \mathrm{~cm} \times 30 \mathrm{~cm}$ in order to comply with the basemap resolution. In the final 109 step, the new dataset was converted from a raster to a vector format, which allowed the 110 calculation of additional parameters. An example of the classification process can be seen in Figs $1112 \mathrm{a}, 2 \mathrm{~b}$, while the green space coverage for each class per park can be seen in Fig.2c. Finally, 112 although the classification process yields small errors among the three classes, the final accuracy 113 is high and did not affect the proportions of green space coverage as shown in Fig. 2c. 
$114 \quad$ Fig. 2

$115 \quad 2.3$ Green space and morphological indicators

116 The indicators presented in Table 2 refer to vegetation-related and morphological variables

117 relevant to the parks themselves or their surrounding environment. The first three indicators refer

118 exclusively to park features, namely: park size $(C A)$, tree coverage (Tree_COV) and grass

119 coverage (Grass_COV). The road $\left(R C O V_{-} 100\right)$ and building coverage (BCOV_100) within a

120 buffer zone of $100 \mathrm{~m}$ around the borders of the parks were also calculated. The $100 \mathrm{~m}$ distance

121 was chosen according to the studies by Tompalski \& Wężyk, (2012) and M'Ikiugu, Kinoshita, \&

122 Tashiro, (2012). In particular, all buildings whose centroids satisfied the 100-meter buffer

123 criterion were selected. Road surfaces were digitized in Google Earth, since the road width is

124 easily recognisable. The distance of $100 \mathrm{~m}$ was selected as the zone that can directly influence the

125 sound environment of the parks. Other indicators used to describe the surrounding sound

126 environment of the parks were: mean distance from major roads (Mean_dist_major) and

127 maximum simulated traffic volume in the adjacent streets of each park (Max_veh). Particularly,

128 “Mean_dist_major" was calculated by averaging the distances $(d 1, d 2, d 3, d 4)$ from all four

129 sides of each park (Eastern, Western, Northern, Southern). However, roads had to be classified in

130 one of the following categories: motorway, ring road or national road. The road classes and the

131 speed data were retrieved from the traffic count database based on the Flemish Traffic Centre

132 (Flemish Traffic Centre, 2015).

133 Table 2 


\subsubsection{Noise mapping}

136 Noise levels were both simulated and measured. In the first case, the impact of the roads adjacent

137 to the parks was simulated using CadnaA sound propagation software (v. 4.5). The UK

138 Calculation of Road Traffic Noise (Department of Transport, Welsh Office, 1988) and ISO

139 9613-B:1996 were used to select the parameters of traffic characteristics and outdoor sound

140 propagation respectively. Traffic data were based on origin-destination matrices built upon

141 automatic and manual traffic counts simulated for the entire road network of Flanders. The final

142 data refers to the number of vehicles per hour (veh/h) for day, evening and night over every road

143 segment of Antwerp's network, during weekdays (Flemish Traffic Centre, 2015).

144 In the simulation, the surrounding environment of the parks was considered as totally reflective

145 with a zero Ground Factor $\left(\mathrm{G}_{\mathrm{out}}=0\right)$, while for the surface area inside the parks four different

146 cases were tested as a sensitivity analysis. In the first case, the Ground Factor $\left(\mathrm{G}_{\text {in }}\right)$ was kept

147 constant $\left(\mathrm{G}_{\mathrm{in}}=1\right)$ and noise levels were calculated - with and without the effect of terrain - using

148 elevation data. In the second case, noise levels were calculated with and without elevation - in

149 order to test the actual effect of terrain - with $\mathrm{G}_{\mathrm{in}}=0.5$ for grass areas and $\mathrm{G}_{\mathrm{in}}=1$ for areas covered

150 with trees. No barriers were present around any of the measured parks during the measurements

151 campaign period, therefore they were not included in the simulation. Finally, receivers in

152 CadnaA were placed every five meters at a height of two meters above the ground, since the aim

153 was to capture the noise variation close to the human scale and not in the building facades.

$154 \quad$ Fig.3 


\subsubsection{Noise measurements}

156 In the second case, portable devices were used to capture the sound variability in the parks, using

157 the approach similar to Schnell et al. (2013). Measurement devices were custom-made Linux158 based sensor network nodes created to incorporate both sound and location recordings. Hardware 159 consisted of a single board computer (Alix 3D3 system board) with the connected 0.1 in 160 microphone (Knowles FG-23329-P07) and a GPS receiver (Haicom HI-204III). The approach of 161 using a small microphone for environmental noise monitoring was verified in a previous study 162 (Van Renterghem et al., 2011). Three of the measurement devices were assembled using the 163 same type of components and placed into the backpacks. Each day before the measurements the 164 devices were calibrated to $94 \mathrm{~dB}$ SPL output level with a class 1 calibrator (Svantek SV 30A). 165 The used software was in-house made (Botteldooren et al., 2013; De Coensel and Botteldooren, 166 2014; Domínguez, et al., 2014), and it included recording of the audio and calculation of 1/3167 octave band levels, eight times per second. Moreover, GPS positions were recorded once each 168 second. The data were saved on a USB card during the walks and transferred to the database 169 after each day of the measurements.

170 Two to three participants - depending on the size of the park - used mobile recording devices 171 carried in the backpacks. The participants were University researchers of the acoustics group and 172 therefore thoroughly aware of the measurements caveats. Moreover, all of them were 173 additionally trained to carefully mind their way of walking in order not to intervene in the 174 recorded sonic environment.

175 The walks were made with a common starting point on the existing paths within the parks, while 176 no specific directional guidelines were given in order to provide the participants with the 177 freedom to move arbitrarily. Additionally, the participants were asked to make stationary 
178 recordings with 10-minute stops every half an hour by placing the backpack on the bench.

179 Finally, to measure the surrounding sound environment, recordings were also performed by

180 walking along the closest roads outside the parks as shown in Fig.4.

181 All noise measurements were performed during August and September 2013 between 11:00 a.m.

182 and 19:00. The total amount of points per park during one day varied between 2,800 and 3,800

183 depending on the park size. For the current analysis, all levels recorded in a single day within the

184 borders of a park were taken into consideration by accumulating all the measurements points

185 from the corresponding devices.

$186 \quad$ Fig.4

187 In the final stage, all measurement points were intersected with the two green space classes

188 (Tree_COV, Grass_COV). Most of the paths in the parks were not recognisable in the image

189 classification; however, the points intersected with the main ones were classified to the closest

190 green space class. Water features, buildings and main paths were easily recognisable and did not

191 affect the accuracy of the final classification. On average 2,056 points were attributed in the tree

192 coverage class and 513 in the grass coverage class per park.

193

194 2.5. Noise indicators

195 The noise level indicators were divided into two categories as displayed in Table 3; simulation-

196 based and measurement-based. The first category includes indicators that describe the entire

197 sound environment according to the simulated traffic conditions around them. The second one

198 encompasses widely adopted indicators ( Hao et al., 2015; Wang \& Kang, 2011) referring in

199 detail to the noise levels recorded with the portable devices in each park. The indicators were

200 calculated for each 10-second time step by accounting for the 1/3-octave band spectrum values 
201 within a moving time window of one minute. Finally, location data (GPS positions) was included 202 and related to the acoustic indicators by interpolating the dataset to the same 10 -second division 203 period.

204 Table 3

205 In the first category, one indicator refers to the minimum and maximum levels of $L_{d}$ using the 206 noise mapping results, while the other calculates the average value of $L_{d(a v g)}$ per park using a 207 Matlab code. The reference area for this calculation is the area only within the park borders. The 208 code was set to recognise the colour range for each noise band and transform the RGB (Red209 Green-Blue) values in noise levels. Noise levels were simulated based on a grid of 5x5 $\mathrm{m}$ in 210 order to capture also small noise variations in the study areas.

211 On the contrary, the second category uses detailed percentiles weighted sound levels (Table 3). It 212 consists of the following indicators: $L_{A 10}, L_{A 50}, L_{A 90}$, and $L_{A e q}$. All of them were initially 213 calculated from the stored measurement data and extracted on the same selected time steps by 214 taking the 1/3-octave band values of one-minute duration.

215 In order to guarantee a representative sampling strategy in the measurement data, a grid-based 216 approach was also applied. The aim of this approach was to aggregate the measurement values 217 within the same grid so as to avoid any possible bias from the fact that smaller parks are 218 expected to have more sampling points within the same sampling period. The applied grid was $21920 \times 20$ m covering the maximum possible width of a single path among the eight parks. The grid 220 size in this case was defined based on specific criteria relevant to the area size of the parks and 221 the paths width. As a result, it had to be bigger than the one of $5 \times 5 \mathrm{~m}$ applied in the simulated 222 noise levels. An identical grid size for both cases would end up in significant increase in 223 calculation time without improving the accuracy of the final results. Furthermore, it would cause 
224 unclassified points in the case where all points would have to be attributed to a single vegetation225 related class.

226 In both cases the percentile indicators were used to get the dynamic characteristics of the sonic

227 environment: $L_{A 50}$ illustrates the average, $L_{A 90}$ the background noise and $L_{A 10}$ the highest values 228 or peaks. Finally, A-weighted equivalent levels $\left(L_{A e q}\right)$ were used due to their overall relationship 229 with the human hearing characteristics.

\subsection{Noise clusters identification}

231 An additional indicator was extracted to identify possible spatial relationships of the noise levels 232 exhibited inside the parks. The calculation of this indicator was performed in two steps. At first, 233 the "Hot Spot Analysis" tool was used to calculate the Getis-Ord (Gi) index (ESRI, 2016c) for 234 each feature in the dataset. The subsequent $z$-scores and $p$-values provided information on 235 whether there are spatial clusters between points of low or high noise levels.

236 The tool works by examining each point within the context of neighbouring points. A point with 237 a high noise level value can only be considered statistically significant $(p \geq .90)$ when surrounded 238 by other points with high values as well. The tool was set to run under the "inverse distance" 239 option; where nearby neighbouring features have a larger influence on the computation than 240 features that are far away. The threshold distance was calculated by the system each time in 241 order to ensure that each point has at least one neighbour. The output feature class giving the 242 confidence level is represented by the "Gi_Bin" field and identifies statistically significant hot 243 and cold spots. It ranges between -3 and +3 . Features in the $( \pm 3)$ bins reflect statistically 244 significant spots with a $99 \%$ confidence level; features in the $( \pm 2)$ bins correspond to a $95 \%$ 245 confidence level and features in the $( \pm 1)$ bins reflect a $90 \%$ confidence level. Zero bin values 246 refer to non-statistically significant points. 
In the second step, the spatial distribution of the points was measured, since the aim was to

248 detect to what extent the difference in sound sources inside and outside the parks can have an

249 effect on the recorded noise levels. In this case the distance from all points to the park's centroid

250 was used as an objective method able to yield comparative results among all parks. Centroid-

251 based solutions are common in spatial analysis with representative examples provided by Jerrett

252 et al. (2004) and Talen (1997).

253 For this analysis, only points of marginal values were used $(\mathrm{Gi}=-3, \mathrm{Gi}=+3, \mathrm{p}<.01)$, since they

254 represent the most significant clusters. For simplification reasons, the possible exhibited clusters

255 were divided into three categories: "introverted", "extroverted" and "random", with an example

256 of the first two to be given in Fig 5. An "extroverted" cluster (Fig.5a) denotes a positive

257 correlation between the distance of each measurement point from the park centroid and the

258 respective noise levels. Practically, this means that higher noise levels have been identified on

259 the borders of the park and there is a decreasing tendency as somebody moves towards the park

260 centroid. On the other hand, an "introverted" pattern (Fig.5b) presents a negative correlation with

261 higher noise levels close to the centroid and a decreasing tendency as somebody moves towards

262 the borders. It should also be made clear that the algorithm can also recognise the cluster of

263 points created by the stationary recordings; however the number of points in this category is

264 small and does not affect the overall correlations.

$265 \quad$ Fig.5.

266 3. Results

2673.1 Noise distribution at point scale

268 Initially, the simulated noise data as presented in Section 2.4.1 showed that the distinction 269 of ground absorption between areas of trees and grass had an additional effect between 0.3 
270 and $1.1 \mathrm{~dB}(\mathrm{~A})$, while the presence of terrain had an effect between 5 and $6.2 \mathrm{~dB}(\mathrm{~A})$.

271 Contrary to these simulated results that investigated the influence of traffic noise from the

272 adjacent roads, measurement noise levels refer to the indicators extracted from the data

273 recorded in each park. For this analysis, $L_{A 10}$ and $L_{A 90}$ were used to represent the marginal

274 cases of peaks and background noise respectively. Therefore, Figs 6a,6b represent the

275 frequency of occurrence of noise levels between 40 and $75 \mathrm{~dB}(\mathrm{~A})$ for each of the two

276 indicators (99\% of measurement points). The same analysis using the grid approach

277 presented in Figs 6c,6d showed that although the curves were quite different, noise levels

278 were similar in average values with the initial frequency approach and only differ by 0.1 to

$2792 \mathrm{~dB}(\mathrm{~A})$ for both indicators.

280 Fig. 6.

281 It can be seen that each park follows a different bell-shaped distribution in both approaches.

282 Using the quartiles for the specific dataset as a reference it is evident that the distribution of $L_{A 90}$

283 is mostly skewed to the left with maximum noise levels around $60 \mathrm{~dB}(\mathrm{~A})$ for all parks apart from

284 Rivierenhof. On the contrary, the La10 distribution presents a higher degree of normality in the

285 curves with values that exceed $70 \mathrm{~dB}(\mathrm{~A})$ in all parks apart from Domein. From both approaches,

286 it is clear that the background noise $\left(L_{A 90}\right)$ presents more fluctuations than $L_{\mathrm{A} 10}$, which further

287 provides an evidence that this can probably be related to traffic.

288 Two groups of parks can be distinguished according to the grid approach for $L_{A 90}$ (Fig.6c). The

289 first group (Sorghvliedt, Nachtegalenpark, Te Boelaerpark and Rivierenhof) contains a

290 maximum number of measurement points between 586 and 1,500. On the contrary, the second

291 group (Domein Hertoghe, Den Brandt, Bisschoppenhof and Stadspark) with smaller parks has a

292 maximum frequency of 100 points. The frequency difference between the two groups can be 
293 attributed both to the park size, since bigger parks are expected to have higher noise variability

294 and to the proximity to busy roads around the parks.

295 A further comparison between the measurements inside the parks and the ones recorded in the

296 surrounding roads is shown in Fig.7. In all cases and for both indicators noise levels were higher

297 outside the parks. These differences ranged between 0.5 and $5.9 \mathrm{~dB}(\mathrm{~A})$ for $L_{A 90}$ and between 1.8

298 and 14.3 for $L_{A 10}$. The average difference for $L_{A 90}$ was $3.2 \mathrm{~dB}(\mathrm{~A})$, while the corresponding value

299 for $L_{A 10} 8.5 \mathrm{~dB}(\mathrm{~A})$. This shows that $L_{A 10}$ was much more diversified outside the parks and $L_{A 90}$ in

300 terms of background noise inside the parks. Possible reasons for this divergence can be attributed

301 to various sound sources; however traffic is the most probable. Actually passing-by cars can

302 produce short events with high dynamic range, which influence the LA10 levels.

$303 \quad$ Fig. 7

304 It was also shown that both $\mathrm{L}_{A 90(\text { avg })}$ and $\mathrm{L}_{A 10(\text { avg })}$ differ by almost $9 \mathrm{~dB}(\mathrm{~A})$ between the quietest

305 and the noisiest park, while the $L_{A 90(S D)}$ ranged between 2.2 and $5.2 \mathrm{~dB}(\mathrm{~A})$ and changed

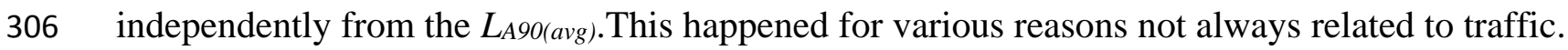

307 For example in some parks such as Bisschoppenhof, Te Boelaerpark, Den Brandt, and

308 Sorghvliedt there were a few points with high levels of $L_{A 90}$ close to their borders. Yet, the

309 majority of peak $L_{A 90}$ values were clustered close to park centres (Nachtegalenpark, Sorghvliedt),

310 usually in short distance from architectural or water features.

311 Human sounds can have a potential contribution in the peak levels of $L_{A 90}$, since traffic noise

312 close to the borders of the parks reduces the acoustic comfort evaluation (Tse et al., 2012) and

313 prompts people's gatherings close to the centres of the parks. Similar differences concerning the

314 acoustic environment of parks and the plurality of soundscapes have previously been reported by

315 Jeon \& Hong, (2015). Vegetation-related parameters can also affect noise levels in an indirect 
way, since large unparticioned grass areas tend to accumulate human activities according to the behavioural mapping outcomes of Goličnik \& Ward Thompson, (2010). For tree areas this is less expected, since a minimum distance of 5 meters was observed between users and tree-lined paths

319 in the above-mentioned study.

320 Out of the eight parks, Bisschoppenhof, Te Boelaerpark, Den Brandt and Sorghvliedt presented 321 the lowest proximity to the ring road or any other national road with an average value of 48.7

$322 \mathrm{~dB}(\mathrm{~A})$ for $L_{A 90}$ and $51.8 \mathrm{~dB}(\mathrm{~A})$ for $L_{A 10}$. The range for $L_{A 10(S D)}$ inside the parks was between 4.8

323 and $6 \mathrm{~dB}(\mathrm{~A})$. As expected, $L_{A 10}$ had a smaller range than $L_{A 90}$ and also smaller variations, since it

324 represents the peak values in the percentile scale and was less susceptible to big fluctuations. The

325 only exception was Rivierenhof park, where the range of values was higher in both noise indices.

326 3.2. Noise distribution at parks scale

327 Noise levels inside the parks as presented in Fig.8 varied between 43 and $78 \mathrm{~dB}(\mathrm{~A})$ in terms of

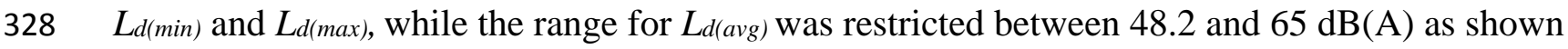
329 in Table 4. The aim of this Table is to mainly highlight the differences among the variations of 330 measured and simulated values, which is more representative than comparing the actual values 331 themselves. Based on these noise levels, Te Boelaerpark was found to be the quietest park, while 332 Rivierenhof the noisiest. Also the noise range presented a great variability among the case study 333 areas ranging between $14 \mathrm{~dB}(\mathrm{~A})$ in Bisschoppenhof and $23 \mathrm{~dB}(\mathrm{~A})$ in Te Boelaerpark.

$334 \quad$ Fig.8

335 Table 4

336 Once the parks were sorted in an ascending form for $L_{d(a v g)}($ Fig.8), two groups were

337 distinguished. The first one involved the first four parks, which presented low noise levels 338 combined with high noise range. The common characteristic among them is that three out of four 
339 (Den Brandt, Sorghvliedt and Te Boelaerpark) are located far from the Ring road or any other 340 National road by at least $370 \mathrm{~m}$. The effect of location on noise levels for these three parks was 341 also depicted in the structure of the box plots (Fig.8), where the minimum noise levels coincided 342 with the $1^{\text {st }}$ quartile (Q1). Practically this suggests that noise variability in these places was very 343 low with high noise levels to appear locally, probably due to the increased traffic volume in one 344 of the surrounding local roads.

345 The second group of parks (Bisschoppenhof, Nachtegalenpark, Rivierenhof and Stadspark) was 346 found to be the noisiest from the traffic perspective with few outliers and a smaller noise range. 347 In all cases, their borders were very close either to the ring road or any other road belonging to 348 the national network. Finally, for all parks the standard deviation (SD) ranged between 2.8 and $3495.4 \mathrm{~dB}(\mathrm{~A})$.

$350 \quad 3.3$ Cluster analysis inside the parks

351 Additional analysis was performed to emphasize the possible patterns exhibited in the 352 measurements data within each park. The pattern investigation was performed only for $L_{A 90,}$ 353 firstly because as an indicator it presents the greatest variation compared to the others and 354 secondly in order to capture the background noise from traffic, whenever this was possible. In 355 order to account for Type I error and spatial dependency, the False Discovery Rate (FDR) option 356 was activated in the Hot Spot analysis options. According to Table 4 there was only one case (Te 357 Boelaerpark), where the $L_{A 90(a v g)}$ was higher $(+3 \mathrm{~dB})$ than the $L_{d(\text { (avg). }}$ Based on these results the 358 expected cluster at this stage would have to be "introverted" in this park and "extroverted" in the 359 other seven cases.

360 However, the results from "Hot Spot" analysis as presented in Fig.9 revealed that the observed 361 cluster for $L_{A 90}$ is quite different from the expected one. In particular, all the three types of 
362 clusters ("introverted", "extroverted" and "random") were detected. The correlation coefficient

$363(r)$ in the eight parks ranged between 0.13 and 0.66 in absolute values. Positive correlations

364 denoting an "extroverted" cluster were detected in four parks, namely: Domein Hertoghe $(r=$

365 0.47), Nachtegalenpark $(r=0.58)$, Rivierenhof $(r=0.59)$ and Stadspark $(r=0.66)$. Negative

366 correlation coefficient denoting an "introverted" cluster were found in Sorghvliedt $(r=-0.63)$

367 and Te Boelaerpark ( $r=-0.36)$. Finally, weak correlations were detected in Den Brandt $(r=-$

368 0.13) and Bisschoppenhof $(r=-0.38)$, which can be considered as random.

$369 \quad$ Fig.9

370 These results confirm to some extent the hypothesis that the sound environment inside the

371 parks is affected by traffic noise. Nevertheless, a holistic approach of the topic should

372 consider the entire sound sources that can be encountered in the parks (human, natural,

373 mechanical). Currently, it was shown that parks with low simulated noise levels such as Te

374 Boelaerpark and Sorghvliedt ("introverted") were little or not affected at all by the outside

375 traffic conditions. In the case of Park Den Brandt, the absence of clustering can be

376 attributed to the sound sources distribution, since the park is conceivably divided in two

377 parts with all the "hot" points clustered to the right and all the "cold" to the left. On the

378 contrary, parks with higher simulated noise levels ("extroverted") were found to be affected

379 by traffic to a lower or higher extent, since the Pearson correlation coefficient ranged

380 between 0.47 and 0.66 .

381 The observed cluster confirmed the hypothesis in four out of eight cases. For the rest of the

382 parks three possible reasons for the divergence can be assumed. First of all, some

383 information is lost when values are averaged to a single number representing each park.

384 Secondly, the results can be affected by the other sound sources found in the parks (human, 
natural) as well as by the physical characteristics of the environment. For example, in

386 Sorghvliedt, the lake in the centre of the park attracts both human and natural life, making this

387 part more vibrant.

$388 \quad 3.4$ Relations between noise levels and morphological features

389 At this level the parks were investigated as single entities. Possible correlations between the 390 green space or morphological features (Table 2) and recorded noise levels (Table 3) were 391 investigated through the Pearson product-moment correlation coefficient. Out of the five 392 measured noise indicators, three were found to be statistically significant and negatively 393 correlated with "tree coverage" as shown in Fig.10. The first was LA10(avg) $(r=-0.68, n=8, p<.01)$, 394 the second one was $L_{A 90(a v g)}(r=-0.74, n=8, p<.01)$ and the third one was $L_{\text {Aeq }}(\mathrm{r}=-0.66), \mathrm{n}=8$, $395 \mathrm{p}<0.1)$. Results are depicted in Fig.10 with the corresponding $\mathrm{R}^{2}$ values. It was shown that more 396 variance is explained when "Tree_COV" is used as a predictor for $L_{A e q}(\mathrm{~F} 1,6)=4.8, \mathrm{p}=0.07$, $\left.397 \quad \mathrm{R}^{2}=0.45\right)$ compared to $\left.L_{d(a v g)}(\mathrm{F} 1,6)=3.7, \mathrm{p}=0.1, \mathrm{R}^{2}=0.28\right)$.

$398 \quad$ Fig. 10

399 Practically, these results reveal that an increase in the tree coverage can potentially reduce noise 400 levels in the parks both for the background noise $\left(L_{A 90}\right)$ and the high peaks $\left(L_{A 10}\right)$. Similar 401 outcomes have been found in previous studies (Fang, Ling \& Kuntze, 2003; McPherson et al., 402 1997), which show that vegetation and particularly trees can be a substantial parameter in noise 403 distribution. From a perceptual viewpoint, Kuttruff (2006) has mentioned that vegetation has a 404 more psychological than physical effect on sound attenuation. This depicts the multiple effects of 405 vegetation at different levels that can be taken into consideration. Taking this into account, the 406 relationship between vegetation and noise can further be explored in landscape and park design. 
407 Apart from the green space parameters, additional correlations were also detected between the $408 L_{A 90, \max }$ and the road coverage, $(r=0.89, n=8, p<.01)$, as well as between the $L_{A 10, \min }$ and the 409 building coverage $(r=0.73, n=8, p<.01)$. In relation to the building coverage similar results have 410 also been identified by Liu et al., (2014b) and Margaritis \& Kang (2016). These correlations

411 provide an evidence base for the importance of the surrounding environment on the overall noise 412 distribution in the parks. Finally, as far as traffic is concerned, a strong positive correlation was 413 detected $(r=.94)$ between $L_{A 90, \max }$ and the maximum traffic volume in the roads adjacent to the 414 parks. This is also evidence that despite the possible presence of human or natural sounds in the 415 parks, background noise from traffic significantly contributes to the maximum levels of $L_{A 90 .}$ 416 Additional important indicators, such as the mean distance from major roads were found to be 417 correlated with the measured noise at this level of analysis. The overall conclusion of the 418 detected correlations could therefore be that the noise level distribution in the parks can be 419 affected both by green space characteristics and morphological attributes from the surrounding 420 environment.

$421 \quad 3.5$ Noise level comparisons using a park-based and index-based approach

422 The final step of analysis dealt with the possible effect of tree or grass areas in noise indices.

423 This analysis was performed in two levels in order to capture the effect of vegetation in different 424 scales and to account for the possible spatial dependence among the points. The park-based 425 approach refers to the analysis performed per park, while the index-based approach refers to the 426 analysis performed per noise index for all parks.

427

428

\subsubsection{Park-based approach}

429 In the park scale, a simple linear regression analysis was conducted to predict each noise index $430\left(L_{A 10}, L_{A 50}, L_{A 90}, L_{A e q}\right)$ based on two predictors: a) the distance of each measurement point from 
431 the park centroid and b) the binary variable of grass or tree coverage per point. The first predictor

432 can account for the noise variability with respect to the centre of each park, while the second one

433 for the variability referring to the vegetation type of each point. The regression models were

434 checked for residual spatial autocorrelation using the Global Moran's I tool in ArcGIS. It was

435 found that in all cases the $\mathrm{z}$-scores were high $(60<\mathrm{z}<1,975)$ and statistically significant

$436(\mathrm{p}<0.001)$, which denotes a bias in data independence. Practically this means that there are

437 unexplored predictors that need to cover the remaining variance. The effectiveness of the current

438 predictors is presented in Table 5 using the coefficient of determination $\left(\mathrm{R}^{2}\right)$.

439 Table 5

440 From Table 5 it can be seen that there was a very low coefficient of determination $\left(\mathrm{R}^{2}\right)$ ranging 441 mostly between $0 \%$ and 17\%. However, there were particular cases (Stadspark, Rivierenhof), 442 where a higher amount of variance between $20 \%$ and $32 \%$ was explained. In these parks, it was

443 found that the distance from centroid managed to explain more variance than the vegetation 444 coverage (grass, trees). These results are consistent with the respective findings in Fig.10 and 445 denote that the further a person moves away from the centre of these parks, the higher the noise 446 levels are $\left(L_{A 50}, L_{A 90}\right)$. For the vegetation coverage the coefficient of determination $\left(\mathrm{R}^{2}\right)$ showed 447 that it was not possible to use it as a predictor for noise levels in a park-based analysis.

$448 \quad 3.5 .2$ Index-based approach

449 In order to overcome the issue of spatial dependence in the residuals as recognised in the park450 based analysis, a second index-oriented approach was investigated. In this approach, the spatial 451 scale covers all the eight parks at the same time providing a minimum of 1,000 neighbours per 452 point from the eight case studies. In that way data independence was secured supported also by 453 the fact that the Global Moran's index was not possible to be calculated with such a high number 
454 of neighbours per point. In total, four datasets were created, one per noise index including all the 455 corresponding data and an average of 30,504 records per index.

456 An independent sample t-test was then conducted to find out whether the difference between the 457 average noise levels detected in tree areas was significantly different from the noise levels within

458 the grass areas. At first, outliers were removed using the box-plot graph for each park and 459 normality was checked using the frequency distribution and the normal Q-Q plots. The 460 homogeneity of variances was checked with Levene's test and it was found that in all cases it 461 was violated, since equal variances were not assumed. Noise levels for the two groups (grass, 462 trees) differed significantly according to Welch's unequal variances t-test $(\mathrm{p}<0.001)$. In all cases, 463 as shown in Fig.11, levels in grass areas were slightly higher than the respective ones in areas 464 covered by trees. The minimum difference detected between grass and trees points was 0.99 $465 \mathrm{~dB}(\mathrm{~A})$ for $L_{A 10}$. (Fig.11a) and the maximum $1.17 \mathrm{~dB}(\mathrm{~A})$ for $L_{A 90}$, (Fig.11b).

$466 \quad$ Fig. 11

\section{4. Discussion and conclusions}

468 The effect of vegetation and traffic-related parameters on the sound environment was 469 investigated in the eight representative parks of Antwerp. Results were investigated in two 470 different scales using the most appropriate calculation method in each case. Simulated traffic 471 noise levels with higher variation were calculated in park scale and sound recordings of high 472 spatio-temporal resolution and smaller variation at point scale.

473 The results showed that the noise levels in grass areas were slightly higher than the respective

$474 \quad$ values in the areas covered by trees. Similarly, Papafotiou et al.(2004) found that dense

475 vegetation could add 2 to $4 \mathrm{db}(\mathrm{A})$ of extra noise reduction compared to areas with grass or 476 bedding plants. From a different viewpoint, Peschardt, Stigsdotter \& Schipperrijn (2016) found 
477 that "green features" do not seem to be significant for "socialising", but mainly for restoration in

478 urban parks. Finally, from a health perspective, Schnell et al. (2016) recognised the valuable

479 effect of green spaces on stress level reduction.

480 From the morphological viewpoint, tree coverage was also found negatively correlated with

481 noise levels. This comes to confirm previous studies where vegetation was used as a predictor for

482 noise levels in land use regression models coupled with variables related to road or building

483 attributes (Xie, Lu and Chen, 2011; Goudreau et al. 2014). Overall, a next step would be to try

484 and correlate the spatial indicators used in this study with perceptual parameters obtained for the

485 same noise environment as Kothencz and Blaschke (2017) have done.

486 The innovative feature of this approach was the combination of measurement noise data with

487 advanced GIS and statistical tools. Possibly a different way of quantifying the distance between

488 each point and the traffic sources might yield better results compared to the centroid approach.

489 Also, this study focused exclusively on the effect of traffic sources and traffic noise within the

490 eight parks. However, from a realistic viewpoint it is difficult to end up in a solid conclusion

491 without taking into consideration all the active sound sources (human, natural) - apart from

492 traffic - that were recorded within the parks. An automatic source recognition tool can help in the

493 future towards this direction.

494 There were also differences between the simulated $\left(L_{d}\right)$ and measured values $\left(L_{A e q}\right)$ showing that

495 the noise maps are good for an overall estimation of the actual environment, but present errors

496 when it comes to the dynamic acoustic environment within the urban parks. As a limitation of

497 the simulation approach, noise sources did not include the water features which are relevant local

498 noise sources 
As regards the noise distribution in the parks taking into account only the simulated traffic conditions from the adjacent roads, it was found that parks closer to the Ring or National Roads present higher noise levels compared to parks further away. Also, In six out of eight cases the simulated noise levels were higher than the average LAeq showing that the actual noise map could not effectively capture the instantaneous noise levels. The differences ranged between 0.63 and $8.27 \mathrm{~dB}(\mathrm{~A})$ in absolute values. The comparison between the inside and the outside environment showed that $L_{A 90}$ was lower inside the parks by $3.2 \mathrm{~dB}(\mathrm{~A})$ compared to $8.5 \mathrm{~dB}(\mathrm{~A})$ for $L_{A 10}$, on average values. For the measured noise levels in the roads around the parks the overall comparison revealed that $L_{A 10}$ presented higher variability than $L_{A 90}$ concluding that the surrounding environment was noisier as expected. Furthermore, in four out of eight parks an "extroverted" cluster was recognised for $L_{A 90}$ showing that noise levels were higher close to the borders of the parks and lower towards their centre. This further signifies that traffic sources had indeed a significant effect on the sound environment inside the parks.

The correlations between morphological and green space attributes of the parks with noise indicators showed that out of all the variables tested, tree coverage was found to be negatively correlated with $L_{A 90(a v g),} L_{A 10(a v g)}$ and $L_{A e q}$. Additional correlations were also detected between the $L_{A 90(\max )}$ and the road coverage as well as between the $L_{A 10(\min )}$ and the building coverage showing that noise level distribution in the parks can be affected both by green space characteristics and morphological attributes from the surrounding environment.

Finally, in the park-based approach it was found that the distance from the park centroid had a higher effect than vegetation coverage in noise level prediction for some parks. Consequently in these cases, the further a person moves away from the park centroid, the higher the noise levels are. In the rest of them both predictors presented very low correlations with noise levels. On the 
522 other hand, the index-based approach showed that noise levels differed significantly between tree 523 and grass areas. However, in the best case $\left(L_{A 90}\right)$ this difference did not exceeded $2 \mathrm{~dB}(\mathrm{~A})$.

524 At first stage, the results of this study can provide evidence on the understanding of the noise 525 environment within the parks and the extent of differences between the inside and the 526 surrounding environment. In a second stage, they can be taken into account in the design of 527 parks' acoustic environment coupled with landscape design principles and sound masking tools. 528 If these elements are further combined with automated source identification algorithms so as to 529 have an estimation of the contribution of each source on the overall sound pressure level, this 530 would further reinforce the design process on making parks more pleasant and attractive to the 531 public. 


\section{References}

1. Aguilera, I., Foraster, M., Basagaña, X., Corradi, E., Deltell, A., Morelli, X., ... Künzli, N. (2015). Application of land use regression modelling to assess the spatial distribution of road traffic noise in three European cities. Journal of Exposure Science \& Environmental Epidemiology, 25(1), 97-105. http://doi.org/10.1038/jes.2014.61

2. Aletta, F., Margaritis, E., Filipan, K., Romero, V. P., Axelsson, Ö., \& Kang, J. (2015). Characterization of the soundscape in Valley Gardens, Brighton, by a soundwalk prior to an urban design intervention. In In Proceedings of Euronoise (pp. 1547-1552). Maastricht.

3. Aylor. (1972). Noise reduction by vegetation and ground. Journal of the Acoustical Society of America, $51,197-205$.

4. Bodin, T., Albin, M., Ardö, J., Stroh, E., Ostergren, P.-O., \& Björk, J. (2009). Road traffic noise and hypertension: results from a cross-sectional public health survey in southern Sweden. Environmental Health, 8, 1-10. http://doi.org/10.1186/1476-069X-8-38

5. Botteldooren, D., Van Renterghem, T., Oldoni, D., Samuel, D., Dekoninck, L., Thomas, P., ... Dhoedt, B. (2013). The Internet of sound observatories. In Proceedings of Meetings on Acoustics: 21st International Congress on Acoustics (Vol. 19, pp. 1-7). Montreal, Canada. http://doi.org/10.1121/1.4799869

6. Brambilla, G., \& Gallo, V. (2016). QUIETE: a scheme for a new index of the environmental quality of green areas. Noise Mapping, 3(1), 49-58. http://doi.org/10.1515/noise-2016-0004

7. Brambilla, G., Gallo, V., Asdrubali, F., \& D’Alessandro, F. (2013). The perceived quality of soundscape in three urban parks in Rome. The Journal of the Acoustical Society of America, 134(1), 832-9. http://doi.org/10.1121/1.4807811

8. Brambilla, G., Gallo, V., \& Zambon, G. (2013). The soundscape quality in some urban parks in Milan, Italy. International Journal of Environmental Research and Public Health, 10(6), 2348-2369. http://doi.org/10.3390/ijerph10062348

9. Brambilla, G., \& Maffei, L. (2006). Responses to noise in urban parks and in rural quiet areas. Acta Acustica United with Acustica, 92(6), 881-886.

10. Calculation of Road Traffic Noise. (1988). Department of Transport, Welsh Office.

11. Can, A., \& Gauvreau, B. (2015). Spatial categorization of urban sound environments based on mobile measurement. In Euronoise 2015 (pp. 1587-1591).

12. Can, A., Leclercq, L., Lelong, J., \& Botteldooren, D. (2010). Traffic noise spectrum analysis: Dynamic modeling vs. experimental observations. Applied Acoustics, 71(8), 764-770. http://doi.org/10.1016/j.apacoust.2010.04.002

13. Cho, D. S., Kim, J. H., \& Manvell, D. (2007). Noise mapping using measured noise and GPS data. Applied Acoustics, 68(9), 1054-1061. http://doi.org/10.1016/j.apacoust.2006.04.015

14. D’Hondt, E., Stevens, M., \& Jacobs, A. (2013). Participatory noise mapping works! An evaluation of participatory sensing as an alternative to standard techniques for environmental monitoring. Pervasive and Mobile Computing, 9, 681-694. http://doi.org/10.1016/j.pmcj.2012.09.002

15. De Coensel, B., \& Botteldooren, D. (2014). Smart sound monitoring for sound event detection and 
characterization. In Inter-noise 2014 (pp. 1-10). Melbourne, Australia. Retrieved from http://www.acoustics.asn.au/conference_proceedings/INTERNOISE2014/papers/p507.pdf

16. De Coensel, B., De Muer, T., Yperman, I., \& Botteldooren, D. (2005). The influence of traffic flow dynamics on urban soundscapes. Applied Acoustics, 66(2), 175-194. http://doi.org/10.1016/j.apacoust.2004.07.012

17. De Coensel, B., Sun, K., Wei, W., Van Renterghem, T., Sineau, M., Ribeiro, C., ... Botteldooren, D. (2015). Dynamic noise mapping based on fixed and mobile sound measurements. In Euronoise (pp. 2339-2344).

18. De Ridder, K., Adamec, V., Bañuelos, a, Bruse, M., Bürger, M., Damsgaard, O., ... Weber, C. (2004). An integrated methodology to assess the benefits of urban green space. The Science of the Total Environment, 334-335, 489-97. http://doi.org/10.1016/j.scitotenv.2004.04.054

19. Domínguez, F., Dauwe, S., Cuong, N. T., Cariolaro, D., Touhafi, A., Dhoedt, B., ... Steenhaut, K. (2014). Towards an environmental measurement cloud: delivering pollution awareness to the public. International Journal of Distributed Sensor Networks, 10(3), 541360. http://doi.org/10.1155/2014/541360

20. EEA Techical Report. (2014). Good practice guide on quiet areas. Retrieved from http://eionet.kormany.hu/download/4/52/b0000/Tech 042014 Guide on quiet areas high res.pdf

21. ESRI. (2016a). Hot spot analysis tool. Retrieved from http://desktop.arcgis.com/en/arcmap/10.3/tools/spatial-statistics-toolbox/h-how-hot-spot-analysisgetis-ord-gi-spatial-stati.htm

22. ESRI. (2016b). Maximum Likelihood Classification Algorithm. Retrieved from http://desktop.arcgis.com/en/arcmap/10.3/tools/spatial-analyst-toolbox/how-maximum-likelihoodclassification-works.htm

23. ESRI. (2016c). Wold Imagery basemap. Retrieved from https://www.arcgis.com/home/item.html?id=10df2279f9684e4a9f6a7f08febac2a9

24. European Commission. (2016). Trans-European Transport Networks. Retrieved from http://ec.europa.eu/transport/infrastructure/tentec/tentec-portal/site/en/maps.html

25. European Directive (EC) 2002/49 of the European Parliament and the Council of 25 June 2002 relating to the assessment and management of environmental noise. (2002). Retrieved from http://eur-lex.europa.eu/LexUriServ/LexUriServ.do?uri=OJ:L:2002:189:0012:0025:EN:PDF

26. Fang, C., Ling, D., \& Kuntze, T. O. (2003). Investigation of the noise reduction provided by tree belts. Landscape and Urban Planning, 63, 187-195.

27. Filipan, K., Boes, M., Oldoni, D., De Coensel, B., \& Botteldooren, D. (2014). Soundscape quality indicators for city parks, the Antwerp case study. In Forum Acusticum 2014. Krakow.

28. Flemish Traffic Centre (2015). Verkeersindicatoren snelwegen vlaanderen. Retrieved from http://www.verkeerscentrum.be/pdf/rapport-verkeersindicatoren-2015-v1.pdf

29. Fyhri, A., \& Klæboe, R. (2009). Road traffic noise, sensitivity, annoyance and self-reported health.A structural equation model exercise. Environment International, 35(1), 91-97. http://doi.org/10.1016/j.envint.2008.08.006 
30. Gereb, G. (2013). Real-time updating of noise maps by source-selective noise monitoring. Noise Control Engineering Journal, 61(2), 228-239. http://doi.org/10.3397/1.3702020

31. Gidlöf-Gunnarsson, A., \& Öhrström, E. (2007). Noise and well-being in urban residential environments: the potential role of perceived availability to nearby green areas. Landscape and Urban Planning, 83(2-3), 115-126. http://doi.org/10.1016/j.landurbplan.2007.03.003

32. Goličnik, B., \& Ward Thompson, C. (2010). Emerging relationships between design and use of urban park spaces. Landscape and Urban Planning, 94(1), 38-53.

http://doi.org/10.1016/j.landurbplan.2009.07.016

33. González-Oreja, J. A., Bonache-Regidor, C., \& De La Fuente-Díaz-Ordaz, A. A. (2010). Far from the noisy world? Modelling the relationships between park size , tree cover and noise levels in urban green spaces of the city of Puebla, Mexico. Interciencia, 35, 486-492.

34. Goudreau, S., Plante, C., Fournier, M., Brand, A., Roche, Y., \& Smargiassi, A. (2014). Estimation of spatial variations in urban noise levels with a land use regression model. Environment and Pollution, 3(4), 48-58. http://doi.org/10.5539/ep.v3n4p48

35. Guillaume, G., Can, A., Petit, G., Fortin, N., Palominos, S., Gauvreau, B., .. Picaut, J. (2016). Noise mapping based on participative measurements. Noise Mapping, 3, 140-156. http://doi.org/10.1515/geo-2016-0023

36. Hänninen, O., Knol, A. B., Jantunen, M., Lim, T.-A., Conrad, A., Rappolder, M., ... Mekel, O. C. L. (2014). Environmental Burden of Disease in Europe: Assessing Nine Risk Factors in Six Countries. Environmental Health Perspectives, 122(5), 439-446. http://doi.org/10.1289/ehp.1206154

37. Hao, Y., Kang, J., Krijnders, D., \& Wörtche, H. (2015). On the relationship between traffic noise resistance and urban morphology in low-density residential areas. Acta Acustica United with Acustica, 101(3), 510-519. http://doi.org/10.3813/AAA.918848

38. Hong, J. Y., \& Jeon, J. Y. (2017). Exploring spatial relationships among soundscape variables in urban areas: A spatial statistical modelling approach. Landscape and Urban Planning, 157, 352364. http://doi.org/10.1016/j.landurbplan.2016.08.006

39. Huddart, L. (1990). The use of vegetation for traffic noise screening. Publication of: Transport and Road Research Laboratory. Crowthorne, Berkshire, England. Retrieved from http://trid.trb.org/view.aspx?id=353616

40. ISO 9613-B: Acoustics-Attenuation of sound during propagation outdoors - Part 2: General method of calculation, International Standard Organization, Geneva, Switzerland. (1996). Retrieved from http://www.iso.org/iso/home/store/catalogue_tc/catalogue_detail.htm?csnumber=20649

41. Jang, H. S., Lee, S. C., Jeon, J. Y., \& Kang, J. (2015). Evaluation of road traffic noise abatement by vegetation treatment in a 1:10 urban scale model. The Journal of the Acoustical Society of America, 138(6). http://doi.org/http://dx.doi.org/10.1121/1.4937769

42. Jerrett, M., Arain, A., Kanaroglou, P., Beckerman, B., Potoglou, D., Sahsuvaroglu, T., ... Giovis, C. (2004). A review and evaluation of intraurban air pollution exposure models. Journal Of Exposure Analysis And Environmental Epidemiology, 15, 185. http://doi.org/10.2747/0272-3638.18.6.521

43. Jeon, J. Y., \& Hong, J. Y. (2015). Classification of urban park soundscapes through perceptions of the acoustical environments. Landscape and Urban Planning, 141, 100-111. 
http://doi.org/10.1016/j.landurbplan.2015.05.005

44. Kang, J., Chourmouziadou, K., Sakantamis, K., Wang, B., \& Hao, Y. (2013). COST Action TD0804 Soundscape of European cities and Landscapes. Oxford. Retrieved from http://www.soundscapecost.org/documents/COST_TD0804_E-book_2013.pdf

45. Kothencz, G., \& Blaschke, T. (2017). Urban parks: Visitors' perceptions versus spatial indicators. Land Use Policy, 64, 233-244. http://doi.org/10.1016/j.landusepol.2017.02.012

46. Kragh, U. (1981). Road traffic noise attenuation by belts of trees. International Journal of Agricultural, Biosystems Science and Engineering, 74(2), 235-241. http://doi.org/https://doi.org/10.1016/0022-460X(81)90506-X

47. Kuttruff, H. (2006). Acoustics: An Introduction (1st ed.). CRC Press.

48. Liu, J., Kang, J., Behm, H., \& Luo, T. (2014a). Effects of landscape on soundscape perception: Soundwalks in city parks. Landscape and Urban Planning, 123, 30-40. http://doi.org/10.1016/j.landurbplan.2013.12.003

49. Liu, J., Kang, J., Behm, H., \& Luo, T. (2014b). Landscape spatial pattern indices and soundscape perception in a multi-functional urban area, Germany. Journal of Environmental Engineering and Landscape Management, 22(February), 208-218. http://doi.org/10.3846/16486897.2014.911181

50. M'Ikiugu, M. M., Kinoshita, I., \& Tashiro, Y. (2012). Urban Green Space Analysis and Identification of its Potential Expansion Areas. Procedia - Social and Behavioral Sciences, 35, 449-458. http://doi.org/10.1016/j.sbspro.2012.02.110

51. Ma, X., \& Cai, M. (2013). Rendering of dynamic road traffic noise map based on paramics. Procedia - Social and Behavioral Sciences, 96, 1460-1468. http://doi.org/10.1016/j.sbspro.2013.08.166

52. Maisonneuve, N., Stevens, M., Niessen, M. E., \& Steels, L. (2009). NoiseTube: measuring and mapping noise pollution with mobile phones. In Proceedings of the 4th International ICSC Symposium (pp. 215-228). Thessaloniki. http://doi.org/10.1007/978-3-540-88351-7_16

53. Margaritis, E., \& Kang, J. (2016). Relationship between urban green spaces and other features of urban morphology with traffic noise distribution. Urban Forestry \& Urban Greening, 15, 174-185. http://doi.org/https://doi.org/10.1016/j.ufug.2015.12.009

54. Margaritis, E., \& Kang, J. (2017). Relationship between green space-related morphology and noise pollution. Ecological Indicators, 72, 921-933. http://doi.org/10.1016/j.ecolind.2016.09.032

55. McPherson, E. G., Nowak, D., Heisler, G., Grimmpnd, S., Souch, C., Grant, R., \& Rowntree, R. (1997). Quantifying urban forest structure, function, and value: the Chicago urban forest project. Urban Ecosystems, 1, 49-61. http://doi.org/10.1023/A:1014350822458

56. Murphy, E., \& King, E. A. (2016). Smartphone-based noise mapping: Integrating sound level meter app data into the strategic noise mapping process. Science of the Total Environment, 562, 852-859. http://doi.org/10.1016/j.scitotenv.2016.04.076

57. Nilsson, M. E., \& Berglund, B. (2006). Soundscape quality in suburban green areas and city parks. Acta Acustica United with Acustica, 92, 903-911. 
58. Papafotiou, M., Chronopoulos, J., Tsiotsios, A., Mouzakis, K., \& Balotis, G. (2004). The impact of design on traffic noise control in an urban park. In International Conference on Urban Horticulture (pp. 277-279). http://doi.org/10.17660/ActaHortic.2004.643.35

59. Peschardt, K. K., Stigsdotter, U. K., \& Schipperrijn, J. (2016). Identifying Features of Pocket Parks that May Be Related to Health Promoting Use. Landscape Research, 41(1), 79-94. http://doi.org/10.1080/01426397.2014.894006

60. Pheasant, R. J., Horoshenkov, K. V., \& Watts, G. R. (2010). Tranquillity rating prediction tool (TRAPT). Acoustics Bulletin, 35(6), 18-24.

61. Pirrera, S., De Valck, E., \& Cluydts, R. (2010). Nocturnal road traffic noise: A review on its assessment and consequences on sleep and health. Environment International, 36, 492-498. http://doi.org/https://doi.org/10.1016/j.envint.2010.03.007

62. Rana, R., Chou, C. T., Bulusu, N., Kanhere, S., \& Hu, W. (2015). Ear-Phone: a context-aware noise mapping using smart phones. Pervasive and Mobile Computing, 17, 1-22. http://doi.org/10.1016/j.pmcj.2014.02.001

63. Ryu, H., Park, I. K., Chun, B. S., \& Chang, S. Il. (2017). Spatial statistical analysis of the effects of urban form indicators on road-traffic noise exposure of a city in South Korea. Applied Acoustics, 115, 93-100. http://doi.org/10.1016/j.apacoust.2016.08.025

64. Schnell, I., Potchter, O., Epstein, Y., Yaakov, Y., Hermesh, H., Brenner, S., \& Tirosh, E. (2013). The effects of exposure to environmental factors on Heart Rate Variability: An ecological perspective. Environmental Pollution, 183, 7-13. http://doi.org/10.1016/j.envpol.2013.02.005

65. Schnell, I., Potchter, O., Yaakov, Y., \& Epstein, Y. (2016). Human exposure to environmental health concern by types of urban environment: The case of Tel Aviv. Environmental Pollution, 208, 58-65. http://doi.org/10.1016/j.envpol.2015.08.040

66. Schulte-Fortkamp, B., \& Jordan, P. (2016). When soundscape meets architecture. Noise Mapping, 3(1), 216-231. http://doi.org/10.1515/noise-2016-0015

67. Selander, J., Nilsson, M. E., Bluhm, G., Rosenlund, M., Lindqvist, M., Nise, G., \& Pershagen, G. (2009). Long-term exposure to road traffic noise and myocardial infarction. Epidemiology, 20(2), 272-279. http://doi.org/10.1097/EDE.0b013e31819463bd

68. Szczodrak, M., Kotus, J., Kostek, B., \& Czyżewski, A. (2013). Creating dynamic maps of noise threat using PL-grid infrastructure. Archives of Acoustics, 38(2), 235-242. http://doi.org/10.2478/aoa2013-0028

69. Szeremeta, B., \& Zannin, P. H. T. (2009). Analysis and evaluation of soundscapes in public parks through interviews and measurement of noise. Science of the Total Environment, 407(24), 61436149. http://doi.org/10.1016/j.scitotenv.2009.08.039

70. Talen, E. (1997). The social equity of urban service distribution: an exploration of park access in pueblo, Colorado and Macon, Georgia. Urban Geography, 18(6), 521-541.

71. Tompalski, P., \& Wężyk, P. (2012). LiDAR and VHRS data for assessing living quality in cities - an approach based on 3D spatial indices. In ISPRS - International Archives of the Photogrammetry, Remote Sensing and Spatial Information Sciences - XXII ISPRS Congress (Vol. XXXIX-B6, pp. 
173-176). http://doi.org/10.5194/isprsarchives-XXXIX-B6-173-2012

72. Tse, M. S., Chau, C. K., Choy, Y. S., Tsui, W. K., Chan, C. N., \& Tang, S. K. (2012). Perception of urban park soundscape. The Journal of the Acoustical Society of America, 131(4), 2762. http://doi.org/10.1121/1.3693644

73. Van Renterghem, T., Botteldooren, D., \& Verheyen, K. (2012). Road traffic noise shielding by vegetation belts of limited depth. Journal of Sound and Vibration, 331(10), 2404-2425. http://doi.org/10.1016/j.jsv.2012.01.006

74. Van Renterghem, T., Dominguez, F., Dauwe, S., Touhafi, A., Dhoedt, B., \& Botteldooren, D. (2011). On the ability of consumer electronics microphones for environmental noise monitoring. Journal of Environmental Monitoring, 13(3), 544-52. http://doi.org/10.1039/c0em00532k

75. Wang, B., \& Kang, J. (2011). Effects of urban morphology on the traffic noise distribution through noise mapping: A comparative study between UK and China. Applied Acoustics, 72(8), 556-568. http://doi.org/10.1016/j.apacoust.2011.01.011

76. Wei, W., Van Renterghem, T., De Coensel, B., \& Botteldooren, D. (2016). Dynamic noise mapping: A map-based interpolation between noise measurements with high temporal resolution. Applied Acoustics, 101, 127-140. http://doi.org/10.1016/j.apacoust.2015.08.005

77. Xie, D., Liu, Y., \& Chen, J. (2011). Mapping urban environmental noise: a land use regression method. Environmental Science \& Technology, 45(17), 7358-7364.

http://doi.org/10.1021/es200785x

78. Zannin, P. H. T., Ferreira, A. M. C., \& Szeremetta, B. (2006). Evaluation of noise pollution in urban parks. Environmental Monitoring and Assessment, 118, 423-433. http://doi.org/10.1007/s10661006-1506-6 


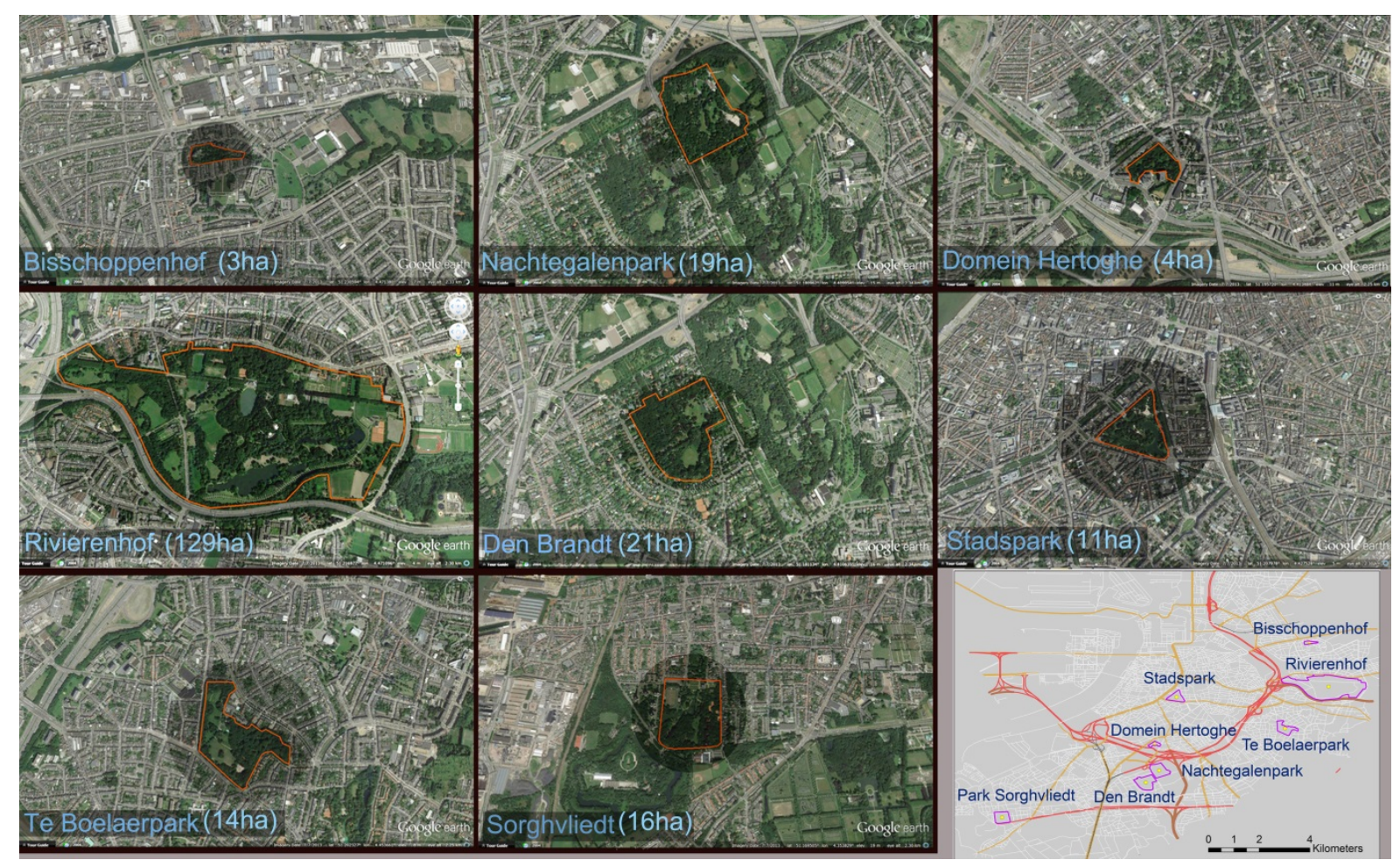

Fig.1. Aerial images of the eight investigated parks in Antwerp, Belgium, from an altitude of $2 \mathrm{~km}$ above ground. The size of the parks is listed next to their names. In bottom right map, the spatial distribution of the eight parks relatively to the city's road network. 

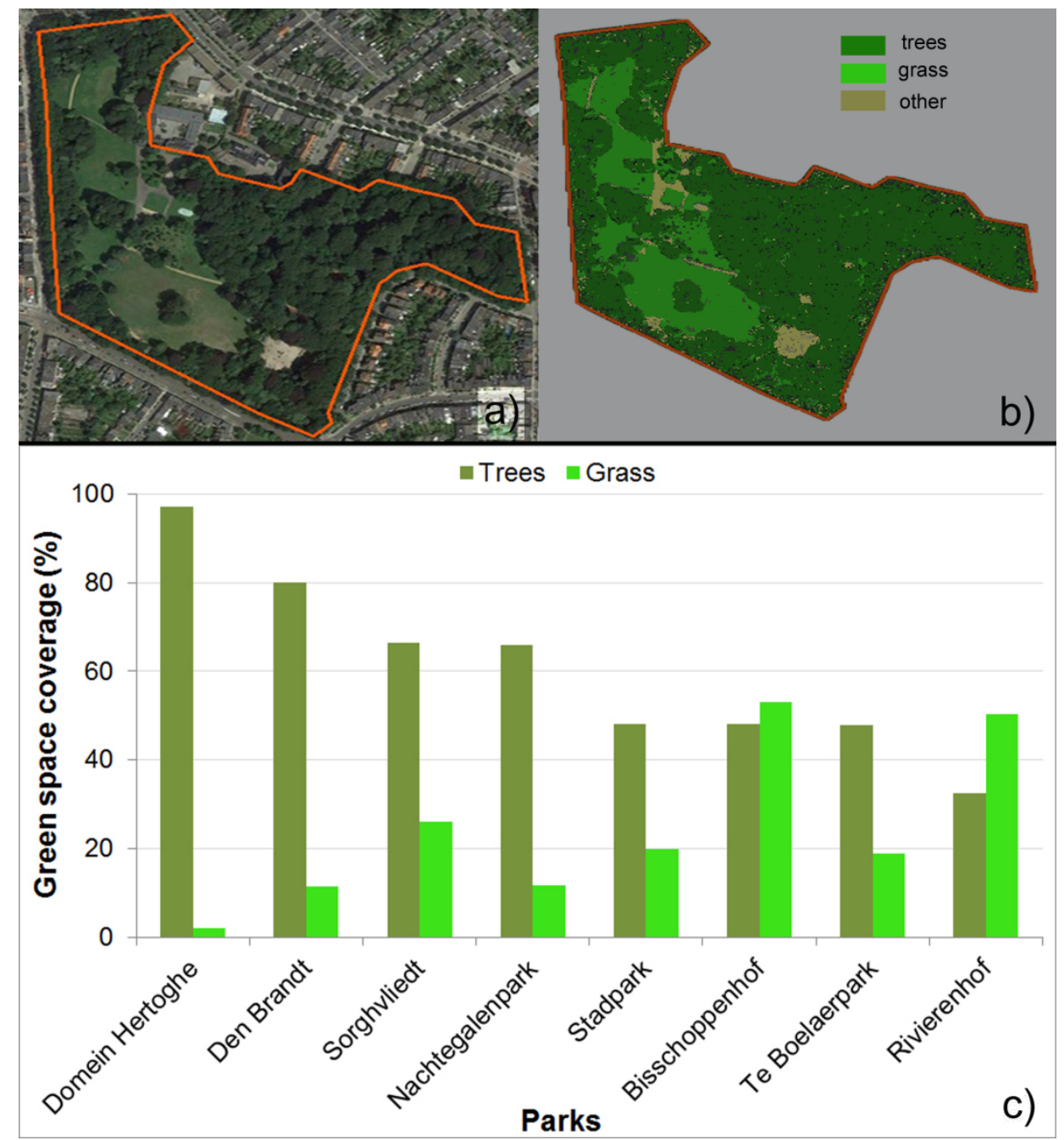

Fig.2. a) Initial satellite image from Imagery basemap (ESRI) for Te Boelaerpark, b) Corresponding results after the Maximum Likelihood classification, c) Green space coverage (ratio) for trees and grass in all parks. 

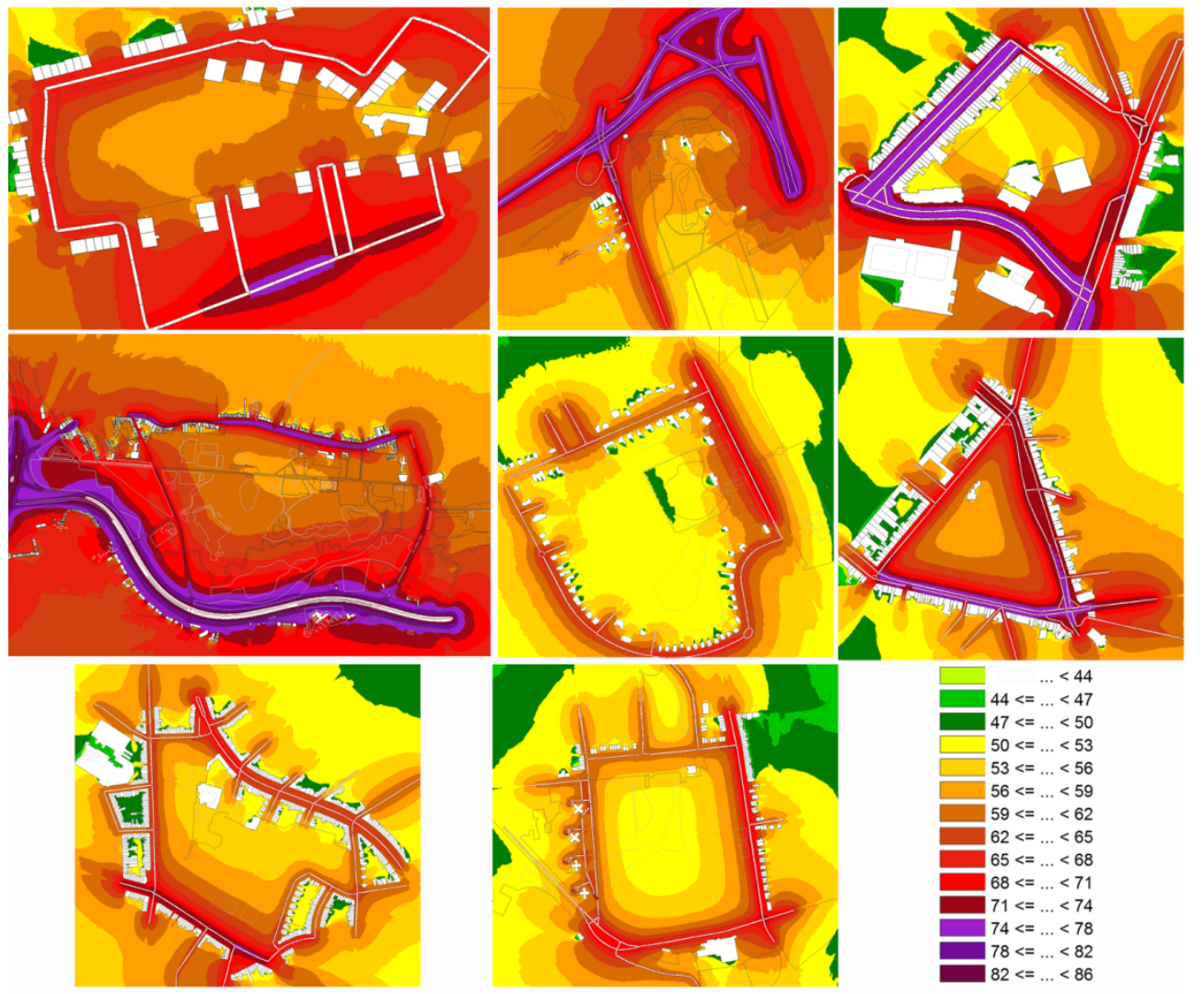

Fig.3. Noise level distribution in the parks and their direct vicinity simulated in CadnaA. The traffic data are based on origin-destinations matrices built upon traffic counts (automatic \& manual) with the traffic to be finally simulated over the idealized traffic network. All data have been retrieved from the Flanders Traffic Centre. Source:

http://www.verkeerscentrum.be/verkeersinfo/verkeerscentrum/vc wie vc 


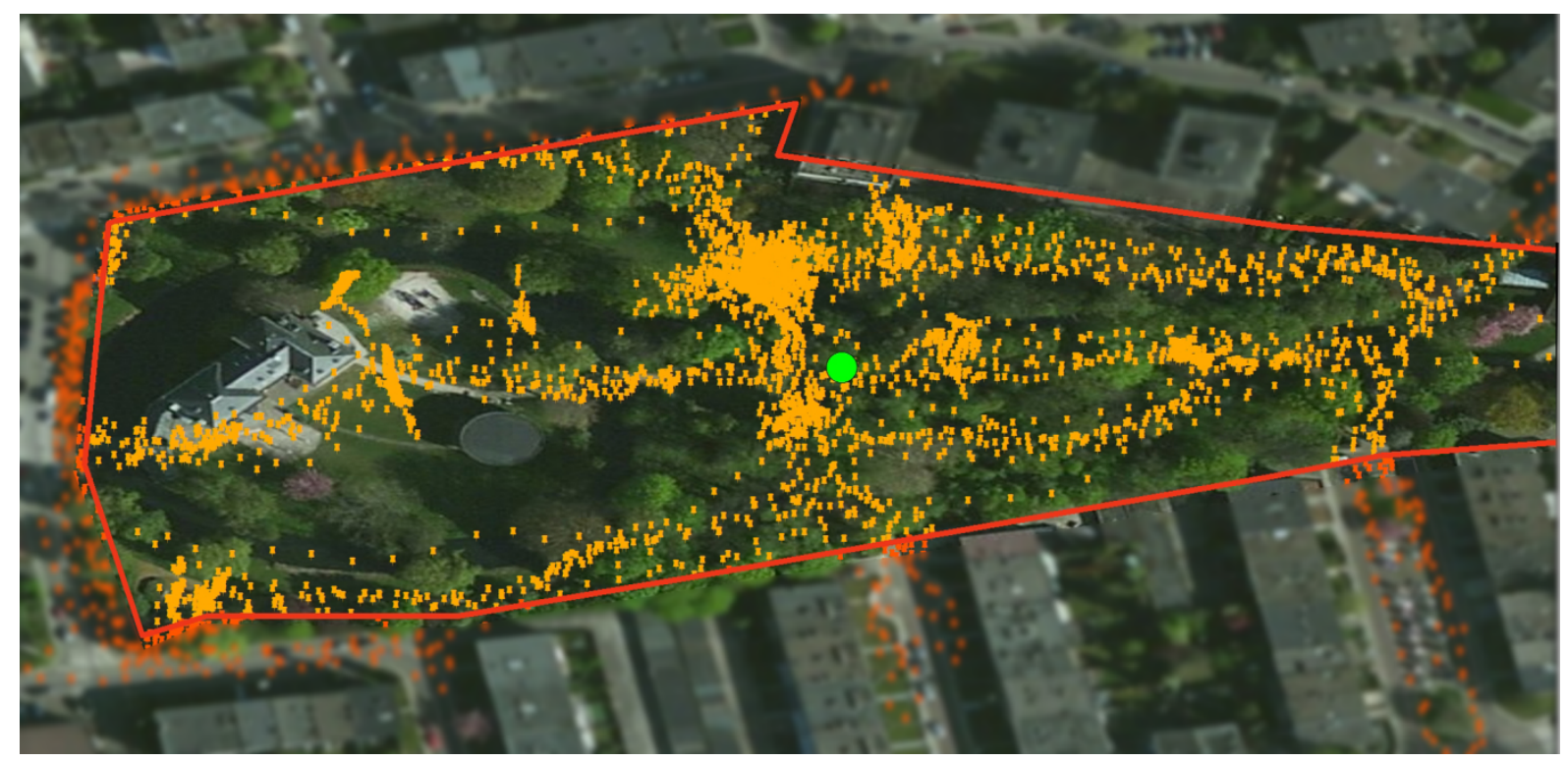

Fig.4. Measurement points distribution inside and outside Bischoppenhof park using an Imagery basemap background. 


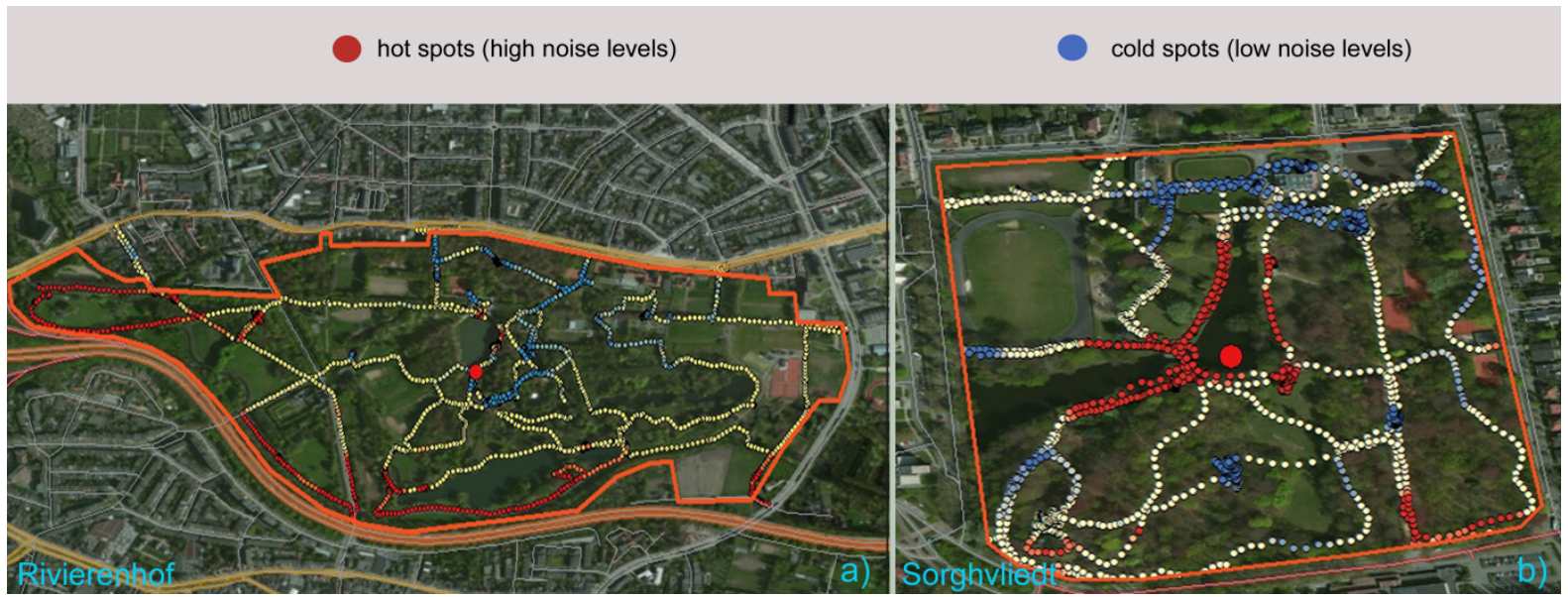

Fig.5. Noise clusters identification: a) "extroverted" and b) "introverted" noise clusters in Rivierenhof and Sorghvliedt respectively with the distribution of hot and cold spots. 


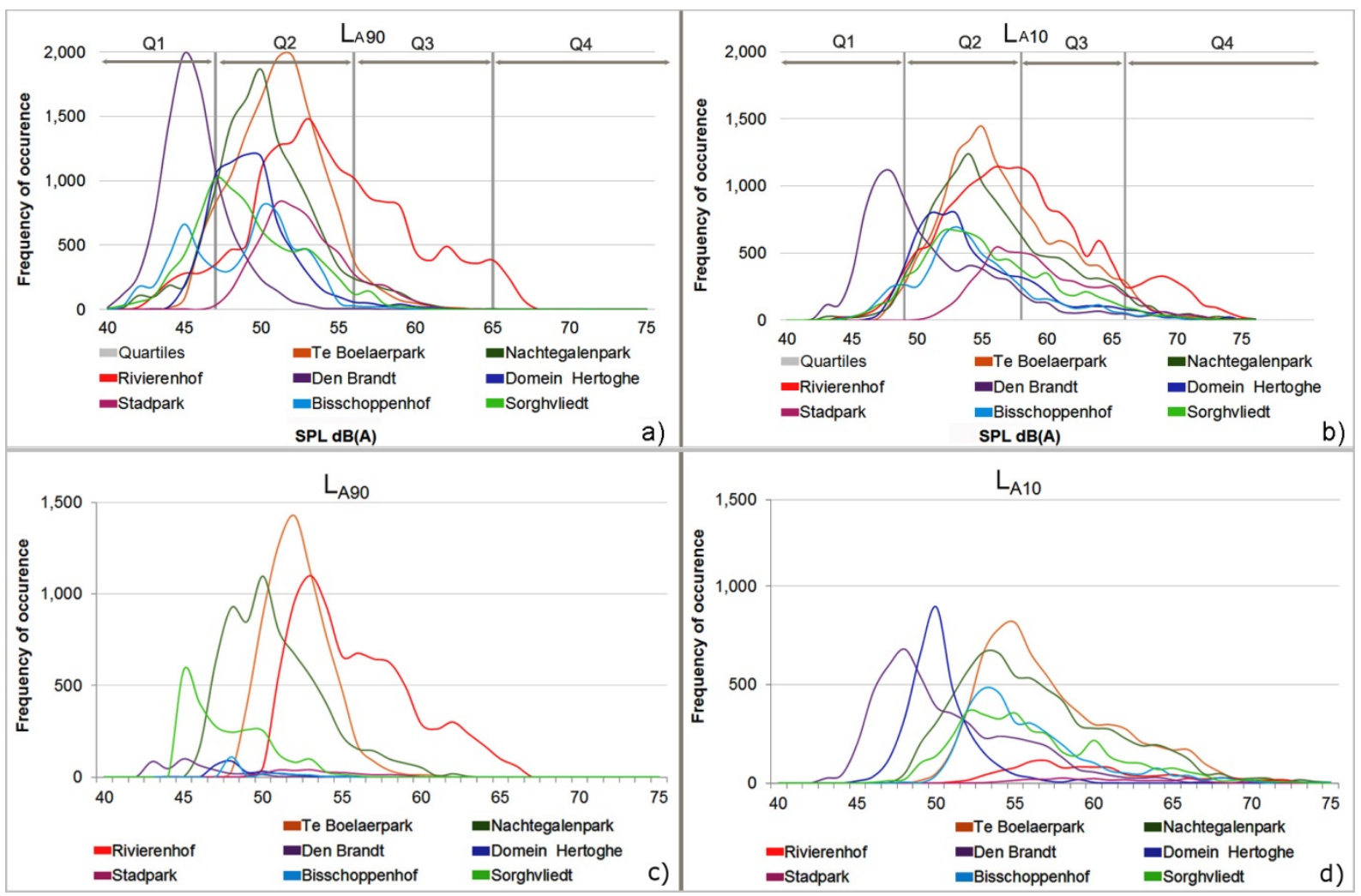

Fig.6. a,b) Frequency of occurrence for $L_{A 90}$ and $L_{A 10}$ based on values per measurement point, c,d) Frequency of occurrence for $L_{A 90}$ and $L_{A 10}$ based on the aggregated values per cell. 


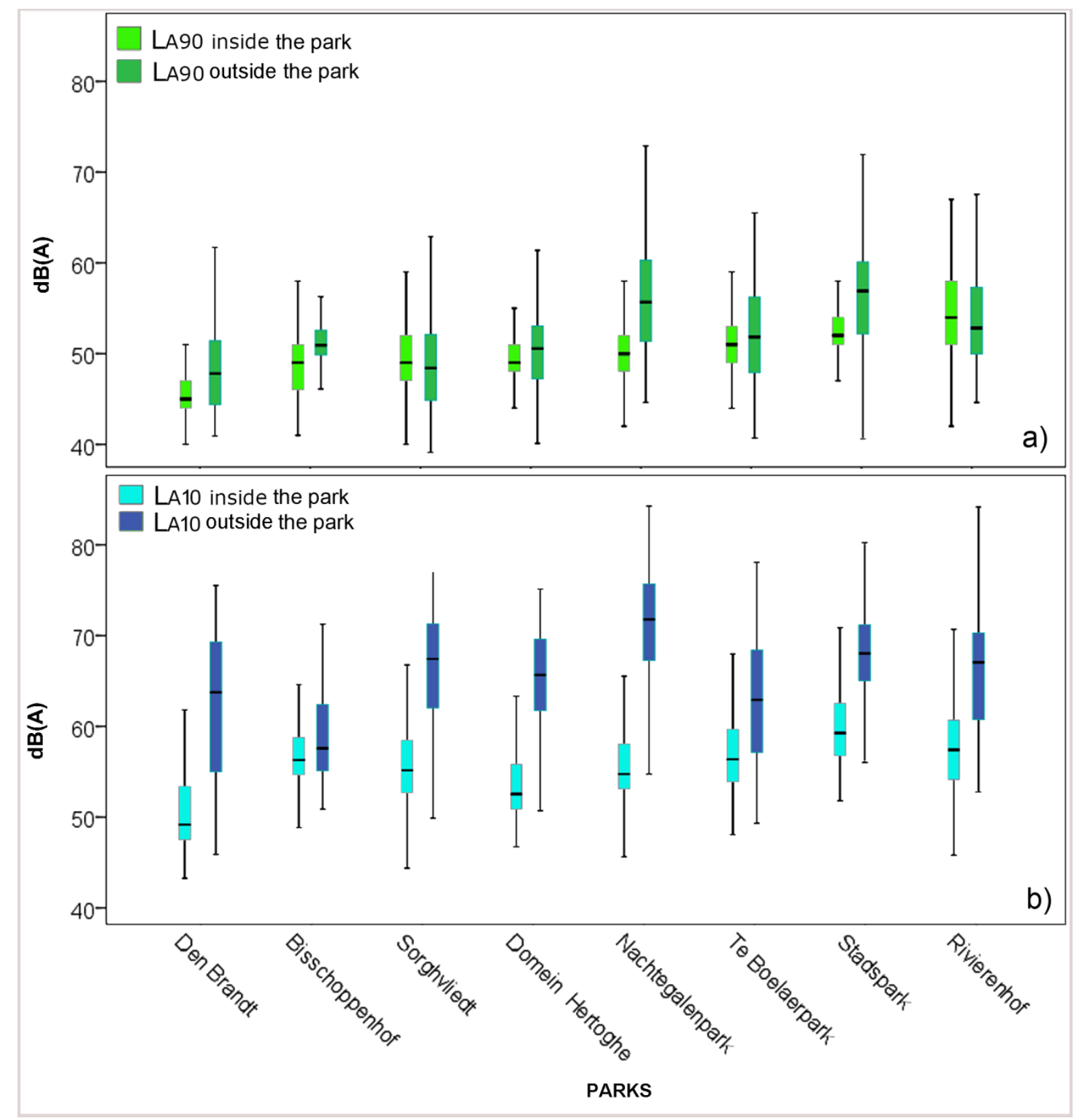

Fig.7. Box plots for(a) $L_{A 90}$ and (b) $L_{A 10}$ describing the sound environment inside and outside the eight parks. Results have been sorted in an ascending form for $L_{A 90}$ (inside). 


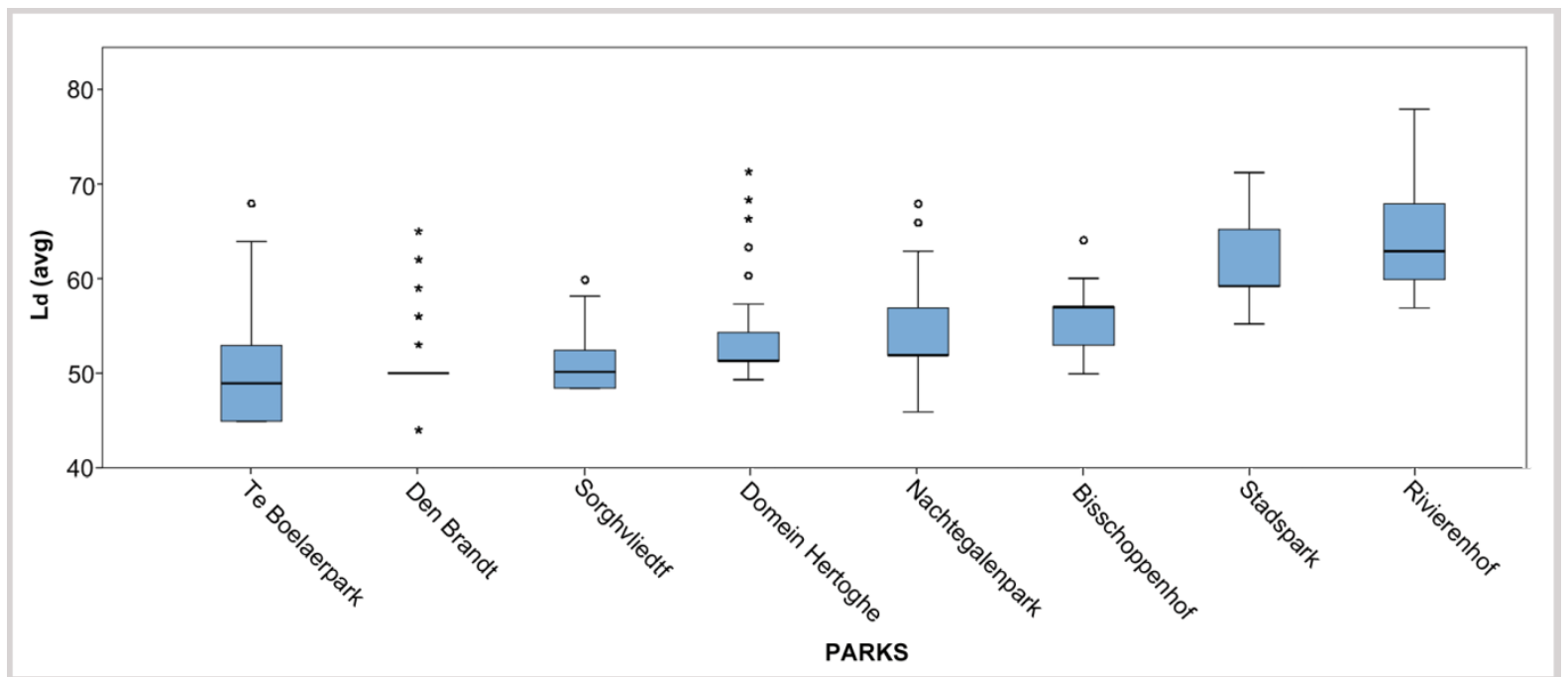

Fig.8. Box plots representing the simulated noise levels within the borders of the eight parks sorted in an ascending form for $L_{d(a v g) \text {. }}$ 


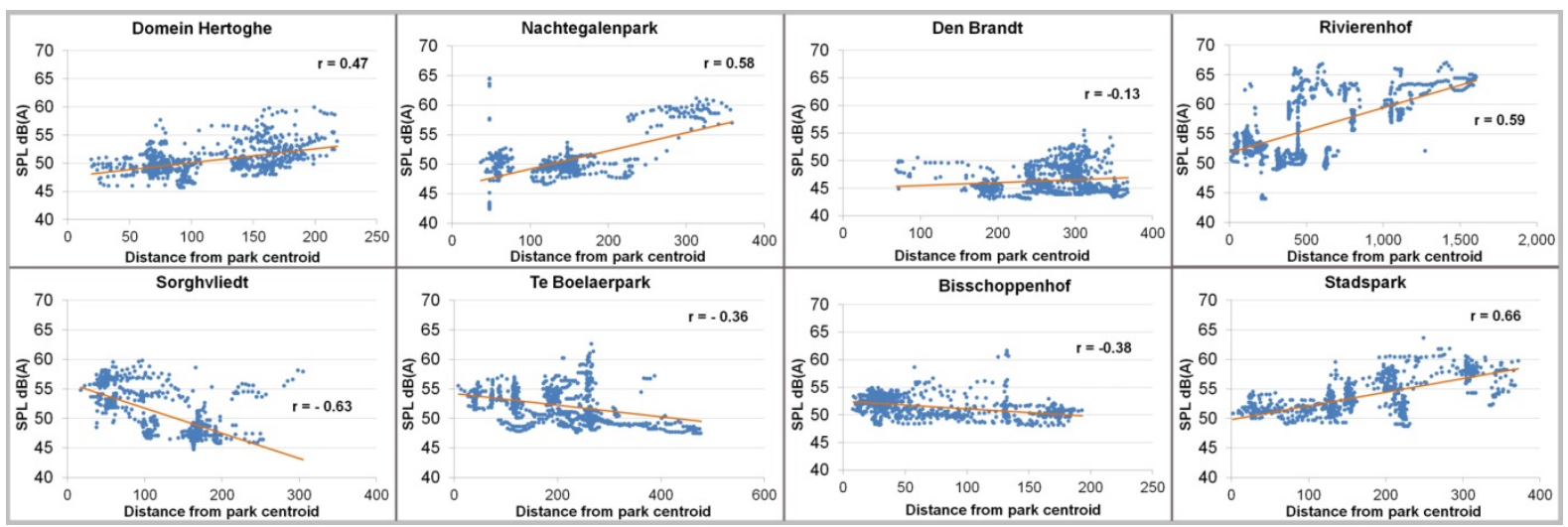

Fig.9. Relationship between the noise levels $\left(L_{A 90}\right)$ of the selected cluster points and the distance from each park centroid ( $\mathrm{p}$-value $<0.001)$. The coefficient of determination $\left(R^{2}\right)$ and Pearson correlation coefficient (r) for the two variables are reported in each graph. 

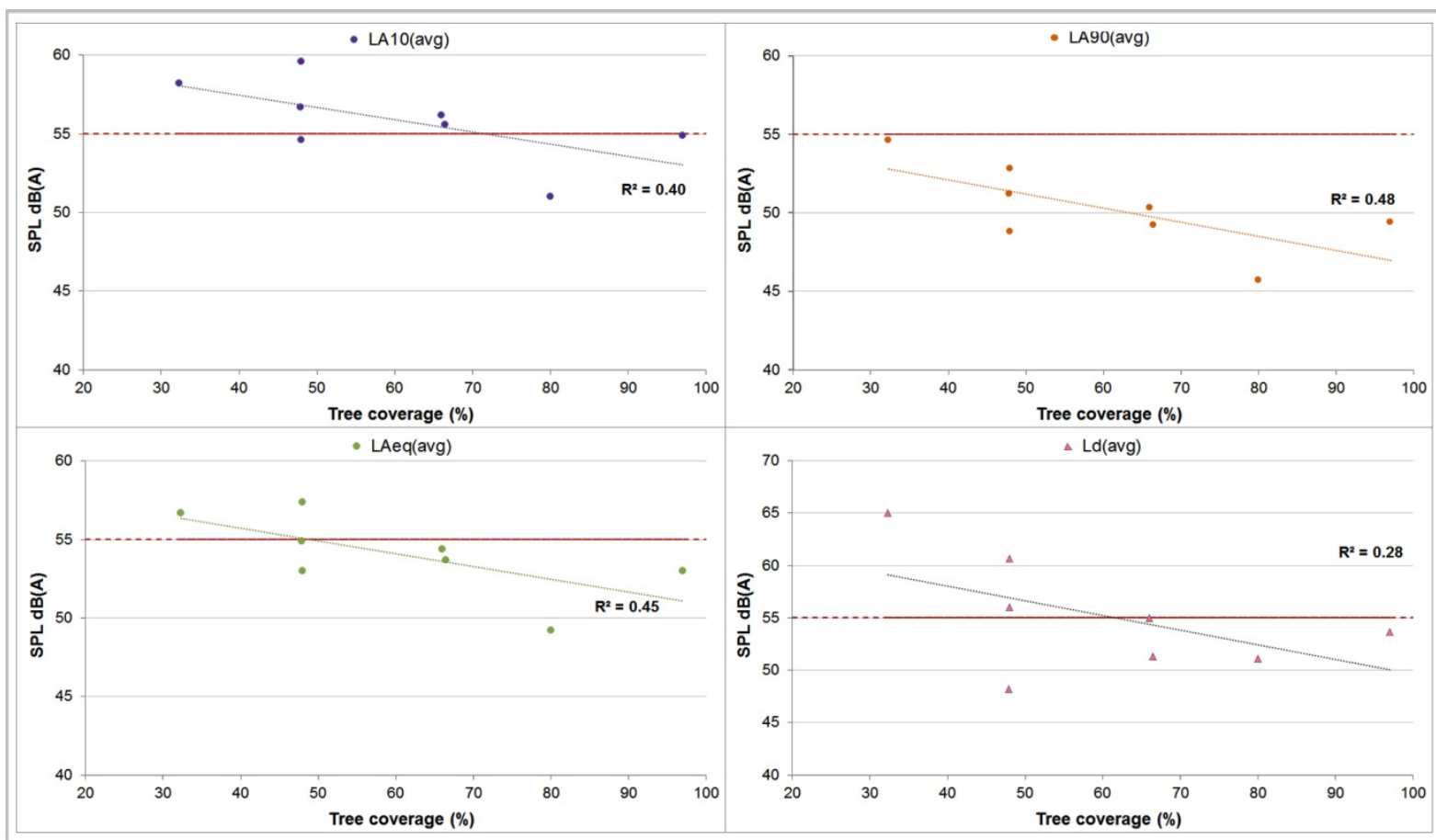

Fig.10. Correlations between tree coverage and $L_{\mathrm{A} 10,} L_{A 90} L_{A e q}$ and $L_{d}$ with the respective $\mathrm{R}^{2}$ values. A cut-off line has been added at $55 \mathrm{~dB}(\mathrm{~A})$ in order to facilitate the comparison among the noise indicators. $\mathrm{L}_{d(\text { avg })}$ refers to simulated noise levels, while the other acoustic indicators refer to measured values in the parks. 


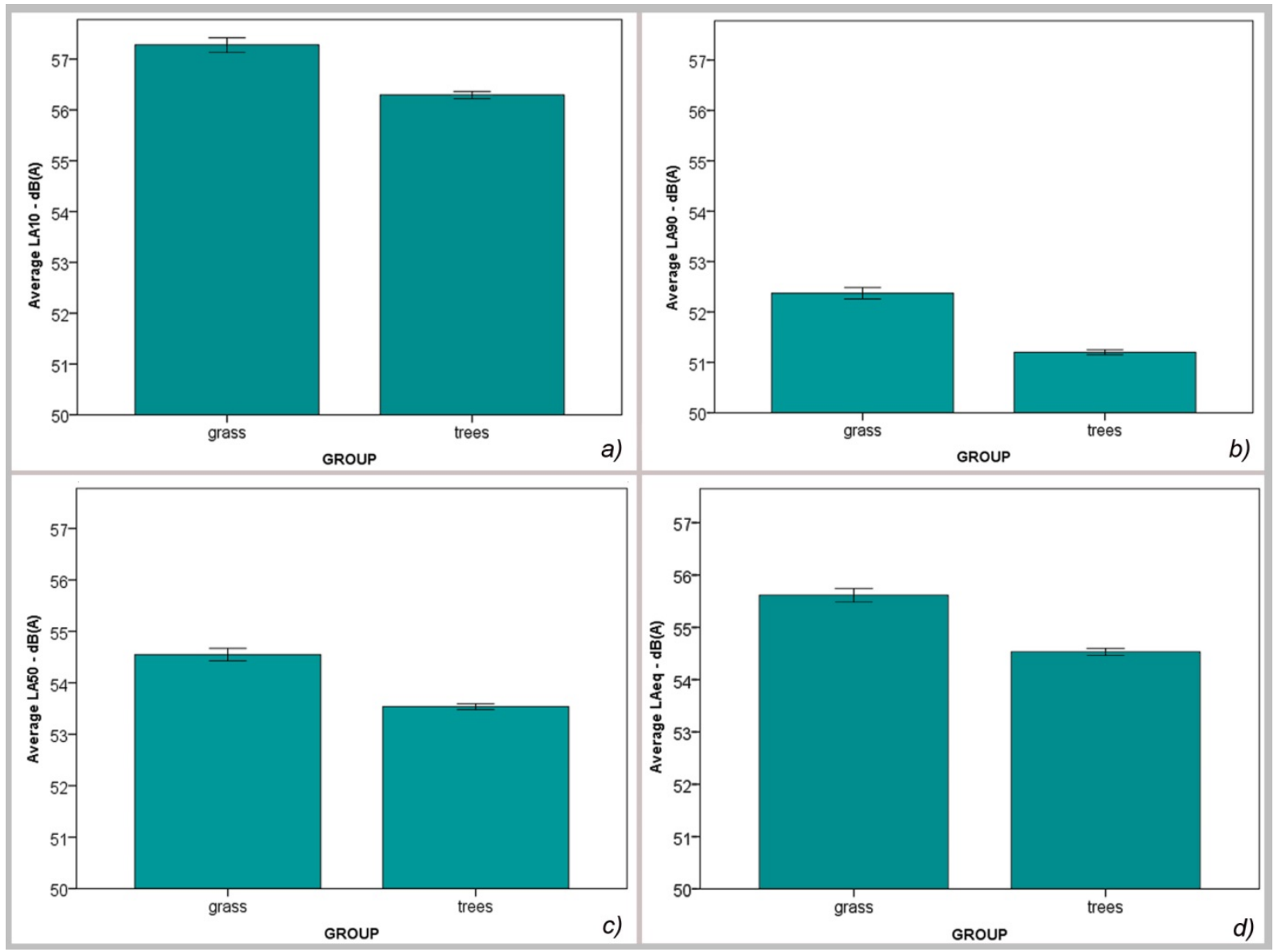

Fig.11. Average noise levels per index for the measurement points classified in tree or grass areas using error bars ( $95 \%$ confidence interval). 


\section{List of tables}

Table 1. Parks size and distance from the roads

\begin{tabular}{clcc} 
A/A & Park & Size (ha) & Distance from the ring/national road (m) \\
\hline 1 & Bischoppenhof & 3 & 128 \\
2 & Domein Hertoghe & 4 & 10 \\
3 & Stadspark & 11 & 13 \\
4 & Te Boelaerpark & 14 & 500 \\
5 & Sorghvliedt & 16 & 637 \\
6 & Nachtegalenpark & 19 & 12 \\
7 & Den Brandt & 21 & 370 \\
8 & Rivierenhof & 129 & 6 \\
\hline
\end{tabular}


Table 2. Vegetation and morphological indicators measured inside and around the parks.

\begin{tabular}{|c|c|c|}
\hline Variable & Symbol & Comment \\
\hline \multicolumn{3}{|c|}{ Vegetation-related indicators } \\
\hline Park size & $C A$ & Total area in hectares. \\
\hline Tree coverage & Tree_COV & Ratio of tree coverage. \\
\hline Grass coverage & Grass_COV & Ratio of grass coverage. \\
\hline \multicolumn{3}{|c|}{ Morphological indicators } \\
\hline Road coverage $(100 \mathrm{~m})$ & $R C O V_{-} 100$ & $\begin{array}{l}\text { Road coverage }\left(\mathrm{m}^{2}\right) \text { measured in a buffer } \\
\text { zone of } 100 \mathrm{~m} \text { around the park borders. }\end{array}$ \\
\hline Building coverage (100m) & $B C O V \_100$ & $\begin{array}{l}\text { Building coverage }\left(\mathrm{m}^{2}\right) \text { measured in a } \\
\text { buffer zone of } 100 \mathrm{~m} \text { around the park } \\
\text { borders. }\end{array}$ \\
\hline Mean distance from major roads & Mean_dist_major & $\begin{array}{l}\text { The average Euclidian distance from all } \\
\text { sides of the park to the closest major road. }\end{array}$ \\
\hline Maximum traffic volume & Max_veh & $\begin{array}{l}\text { The maximum simulated traffic volume } \\
(\mathrm{veh} / \mathrm{h}) \text { in all the streets adjacent to the } \\
\text { park. }\end{array}$ \\
\hline
\end{tabular}


Table 3. Description of all the noise indicators applied in the analysis.

\begin{tabular}{|c|c|c|}
\hline Variable & Category & Comment \\
\hline \multicolumn{3}{|r|}{ Simulation-based indicators } \\
\hline$L_{d}$ & $\min , \max$, avg & $\begin{array}{l}\text { Day noise levels based on traffic flows calculated in } \\
\text { CadnaA and Matlab. }\end{array}$ \\
\hline \multicolumn{3}{|c|}{ Measurement-based indicators } \\
\hline$L_{A 10}$ & $\min , \max$, avg & $\begin{array}{l}\text { A-weighted sound pressure level exceeded } 10 \% \text { of the } \\
\text { measurement period. }\end{array}$ \\
\hline$L_{A 50}$ & $\min , \max$, avg & $\begin{array}{l}\text { A-weighted sound pressure level exceeded } 50 \% \text { of the } \\
\text { measurement period. }\end{array}$ \\
\hline$L_{A 90}$ & $\min , \max$, avg & $\begin{array}{l}\text { A-weighted sound pressure level exceeded } 90 \% \text { of the } \\
\text { measurement period (background noise). }\end{array}$ \\
\hline$L_{\text {Aeq }}$ & $\min , \max , \operatorname{avg}$ & A-weighted equivalent sound pressure level. \\
\hline
\end{tabular}


Table 4. Average simulated and measured noise levels in the eight parks sorted in an ascending form for $L_{d(a v g) .}$ Standard deviation values are presented in parenthesis in each case. Measured values have been calculated by averaging the point levels inside the parks over the entire measurement period (11:00am - 19:00pm).

\begin{tabular}{lc|ccc}
\hline Parks & Simulated & \multicolumn{3}{|c}{ Measured } \\
\hline Te Boelaerpark & $L_{d(\text { avg })}$ & $L_{\text {Al0(avg) }}$ & $L_{A 90(a v g)}$ & $L_{\text {Aeq(avg) }}$ \\
Den Brandt & $48.2( \pm 5.4)$ & $56.7( \pm 4.8)$ & $51.2( \pm 2.9)$ & $54.92( \pm 4.6)$ \\
Sorghvliedt & $51.1( \pm 2.8)$ & $51.0( \pm 5.3)$ & $45.7( \pm 2.3)$ & $49.21( \pm 4.6)$ \\
Domein Hertoghe & $51.3( \pm 4.6)$ & $55.6( \pm 5.2)$ & $49.2( \pm 3.5)$ & $53.67( \pm 5.2)$ \\
Nachtegalenpark & $53.7( \pm 4.3)$ & $54.9( \pm 5.4)$ & $49.4( \pm 2.7)$ & $53.02( \pm 5.0)$ \\
Bisschoppenhof & $55.0( \pm 4.0)$ & $56.2( \pm 5.2)$ & $50.3( \pm 3.4)$ & $54.37( \pm 5.2)$ \\
Stadspark & $56.0( \pm 2.8)$ & $54.6( \pm 5.0)$ & $48.8( \pm 3.6)$ & $53.04( \pm 5.4)$ \\
Rivierenhof & $60.7( \pm 4.2)$ & $59.6( \pm 4.6)$ & $52.8( \pm 2.9)$ & $57.44( \pm 4.4)$ \\
\hline
\end{tabular}


Table 5. The effect of each predictor $\left(\mathrm{R}^{2}\right)$ in the respective noise indices."D_centr" denotes the distance from the park centroid and "Cover" stands for the binary variable of grass and tree coverage per point.

\begin{tabular}{|c|c|c|c|c|c|c|c|c|c|}
\hline \multirow{3}{*}{$\mathbf{A} / \mathbf{A}$} & \multirow{3}{*}{ Parks } & \multicolumn{2}{|c|}{$L_{A e q}$} & \multicolumn{2}{|c|}{$L_{A 10}$} & \multicolumn{2}{|c|}{$L_{A 50}$} & \multicolumn{2}{|c|}{$L_{A 90}$} \\
\hline & & D_centr & Cover & D_centr & Cover & D_centr & Cover & D_centr & Cover \\
\hline & & & & & $\mathrm{R}^{2}$ & $\mathrm{R}^{2}$ & $\mathrm{R}^{2}$ & $\mathrm{R}^{2}$ & $\mathrm{R}^{2}$ \\
\hline 1 & Stadspark & 0.21 & 0.01 & 0.22 & 0.01 & 0.32 & 0.02 & 0.26 & 0.01 \\
\hline 2 & Rivierenhof & 0.20 & 0.03 & 0.17 & 0.03 & 0.20 & 0.03 & 0.29 & 0.03 \\
\hline 3 & Te Boelaerpark & 0.00 & 0.05 & 0.00 & 0.04 & 0.00 & 0.03 & 0.03 & 0.02 \\
\hline 4 & Nachtegalenpark & 0.08 & 0.07 & 0.11 & 0.02 & 0.08 & 0.00 & 0.09 & 0.02 \\
\hline 5 & Bisschoppenhof & 0.00 & 0.00 & 0.00 & 0.01 & 0.00 & 0.01 & 0.01 & 0.01 \\
\hline 6 & Sorghvliedt & 0.00 & 0.04 & 0.03 & 0.03 & 0.05 & 0.01 & 0.13 & 0.01 \\
\hline 7 & Domein Hertoghe & 0.04 & 0.01 & 0.04 & 0.01 & 0.12 & 0.01 & 0.11 & 0.00 \\
\hline 8 & Den Brandt & 0.04 & 0.07 & 0.05 & 0.07 & 0.03 & 0.03 & 0.01 & 0.01 \\
\hline
\end{tabular}

